\title{
An Experimental Study on the Smoke Behavior and Ensuring the Safety of Staircases in a Station Building During a Fire \\ - Air Current Control in an Underground Station by a Passive Safety System -
}

\author{
${ }^{1}$ Takeshi Tokunaga, ${ }^{1}$ Kenji Amano, ${ }^{1}$ Daisuke Oiwa, ${ }^{2}$ Seiji Uchiyama, \\ ${ }^{3}$ Masayuki Mizuno, ${ }^{4}$ Yoshihumi Ohmiya, ${ }^{3}$ Takao Wakamatsu and ${ }^{5}$ Makoto Tsujimoto \\ ${ }^{1}$ Graduate Student, Tokyo University of Science, Japan \\ ${ }^{2}$ Researcher, R\&D Division, SANKI Engineering Co., Ltd., Japan \\ ${ }^{3}$ Center for Fire Science and Technology, Tokyo University of Science, Japan \\ ${ }^{4}$ Dept. of Architecture, Faculty of Science and Technology, Tokyo University of Science, Japan \\ ${ }^{5}$ Dept. of Architecture, Faculty of Engineering, Tokyo University of Science, Japan
}

\begin{abstract}
For underground station buildings, a passive safety system is proposed for energy conservation under daily use and for evacuation safety in case of a fire. The stack effect by a solar chimney and the ambient air cooling effect by dry mist, which have been examined in recent years, are used in the proposed system. During any period of the year, the proposed system controls the air current in the direction of "outside air $\rightarrow$ staircase $\rightarrow$ concourse and platform $\rightarrow$ solar chimney $\rightarrow$ outside air ". If a fire occurs under this status, the safety of staircases will be secured because smoke will be discharged through chimneys.

When adopting this system for an underground station building, it is necessary to check the boundary conditions in the building for effective system operation. Therefore, in the present study, a model as small as 1/20 the size of an actual station building was fabricated, and experiments were conducted using scaling laws.

Keywords: Underground station, Tunnel, Model experiment, Hanging wall, Smoke behavior
\end{abstract}

\section{INTRODUCTION}

Currently, underground station buildings in Japan have a variety of active equipment that is actuated in the case of a disaster. However, their operation reliabilities are not guaranteed, as is evidenced by a fire at Akasakamitsuke Station in August, 2004 that injured two persons because existing smoke control equipment failed to function.

If a system that makes the daily air current in a station building available for smoke control during a fire and that ensures evacuation safety is constructed, the reliability of fire safety will be improved greatly. Furthermore, for global environmental issues, 
it is preferable that the air current in the station building also be used for ventilation and air-conditioning and that the required energy is smaller than that for mechanical air-conditioning equipment.

The passive safety system proposed in the present study incorporate the stack effect by solar chimneys [1] and the ambient air cooling effect by dry mist [2] which have been researched in recent years into a station building project to ensure that the daily air current remains flowing in the same direction so that the behavior of smoke from a fire will not hinder evacuation without mechanical control.

Under this system, screen doors are installed on the platform in order to separate the inside of the station building from the tunnel so as to aid air current control in the station building. Under these conditions, air is exhausted through solar chimneys. In addition, dry mist is sprayed above the staircase entrance to cool the ambient air, and a descending air current is generated in the staircases. The air current is then maintained in the direction of "outside air $\rightarrow$ staircase $\rightarrow$ concourse and platform $\rightarrow$ solar chimney $\rightarrow$ outside air ". This system solves the problem of operation reliability and contributes to energy conservation, because this system reduces the air-conditioning load as a natural ventilation system in the summertime $\left({ }^{*} 1\right)$ and secures sufficient performance for evacuation safety as a smoke control system in the case of a fire (Figurel).

When adopting this system for an underground station building, it is necessary to check the boundary conditions in the building for effective system operation. More specifically, it is necessary to determine the size of a solar chimney for effective air supply and exhaust, as well as the design conditions of a hanging wall and other conditions for preventing smoke inflow into a staircase. Therefore, in the present study, a model as small as 1/20 the size of an actual station building was fabricated and experiments were conducted.

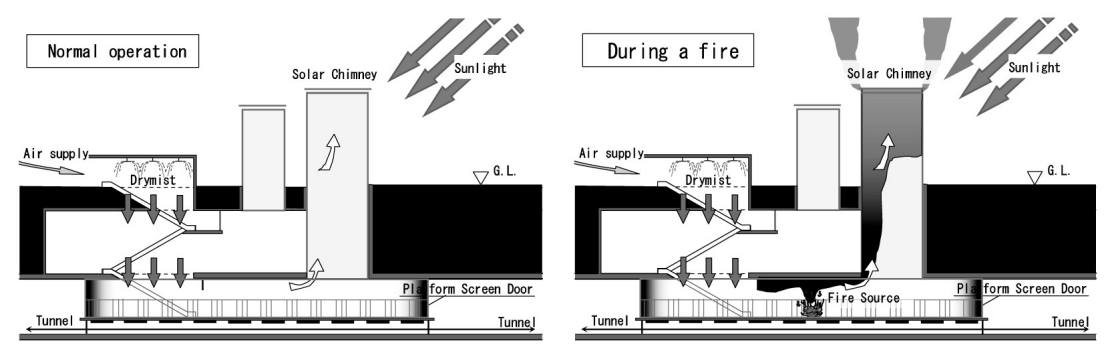

Figure 1 Conceptual diagram of the proposed passive safety system

\section{OUTLINE OF BASIC MODEL EXPERIMENT}

\subsection{Experimental Facilities}

Figures 2 and 3 show a picture of the experimental model and its cross sections and planes. The model was as small as $1 / 20$ an actual station building whose size is $200 \mathrm{~L} \times 15 \mathrm{~W}$ $\times 10 \mathrm{H} \mathrm{m}^{3}$. 
In order to investigate the smoke behavior, the smoke layer temperature, and the ventilation and smoke control performance, the temperature was measured at A to F, a, b, and (1) to (4), and the air current velocity was measured at the center of the air supply opening and at the exhaust opening. At each measurement position, a thermocouple was installed at every $100 \mathrm{~mm}$ up to $300 \mathrm{~mm}$ from the floor and at every $50 \mathrm{~mm}$ thereafter.

Since it was difficult to install a dry mist sprayer or a solar chimney in the model experiment, instead of a dry mist device, a chiller was installed above the staircase and a planar electric heater set to $60^{\circ} \mathrm{C}$ (referring to Document [1]) was installed on the side wall of the chimney instead of a solar chimney.

For the chiller, iron piping was installed in a box in order to allow refrigerated water flow. This caused the temperature of the air inside the box to be approximately $3^{\circ} \mathrm{C}$ lower than that outside [2] and allowed cool air flow into the staircase by natural convection. Thus, an effect similar to the ambient air cooling effect by dry mist was reproduced. Figure 4 shows the internal structure of the chiller.

On one sidewall in the chimney, a planar electric heater was installed in order to reproduce the temperature rise of a northern wall or glass by the absorption of solar radiation heat. Figure 5 shows the various chimneys used in the experiments. The chimney height was $250 \mathrm{~mm}$ or $500 \mathrm{~mm}$. The chimney had cross-sectional area equals to $0.5,1.0$, or 2.0 times the air supply opening area and is $300 \times 300,425 \times 425$, or $600 \times$ $600 \mathrm{~mm}^{2}$. For all of the experiments in Sections 2 and 3, a planar electric heater was installed in the direction shown in Figure 3(i) "Plane of model pattern I."

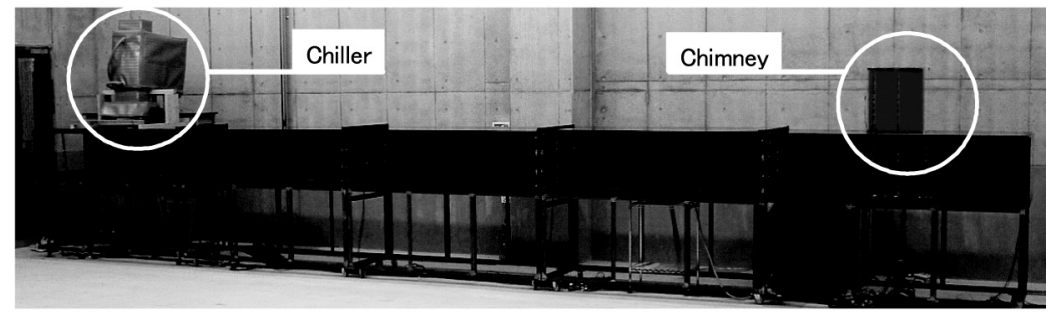

Figure 2 Picture of the 1/20 scale model (Model pattern I)

Table 1 lists the equipment used in the experiments

\begin{tabular}{l|l|r}
\hline \multicolumn{1}{c|}{ Measurement item } & \multicolumn{1}{c|}{ Equipment } & Measurement accuracy \\
\hline Tempreture & T-type thermo couple $\phi 0.2 \mathrm{~mm}$ & $\pm(0.02 \% \mathrm{rdg}+0.2) \mathrm{K}$ \\
\hline \multirow{3}{*}{ Air current velocity } & Hot-wire anemometer (Directional characteristics) & $\pm(3 \% \mathrm{rdg}+0.1) \mathrm{m} / \mathrm{s}$ \\
\cline { 2 - 3 } & Hot-wire anemometer (Non-directional characteristics) & $\pm 0.02 \mathrm{~m} / \mathrm{s}$ \\
\cline { 2 - 3 } & Pitot tube (Directional characteristics) & Based on a differential manometer \\
\hline Differential pressure & Ultra low range differential pressure transducer (Diaphragm) & $\pm 0.125 \mathrm{~Pa}$ \\
\hline Pyrogen unit & Planar electric heater & - \\
\hline Instrument for visualization & Argon ion laser $80 \mathrm{~mW}$ & - \\
\hline Fire source & Burner which size is $100 \times 100 \mathrm{~mm}^{2}$ (Fuel: LP gas $\%$ ) & - \\
\hline
\end{tabular}

※ Only used in experiments for measuring the amounts of ventilation in Sections 5 and 6

※ Components in LP gas used in the experiments :

Propane: $97.7 \%$, I sobutene:1.2\%, Ethane:0.9\%, Normal butane:0.2\% 


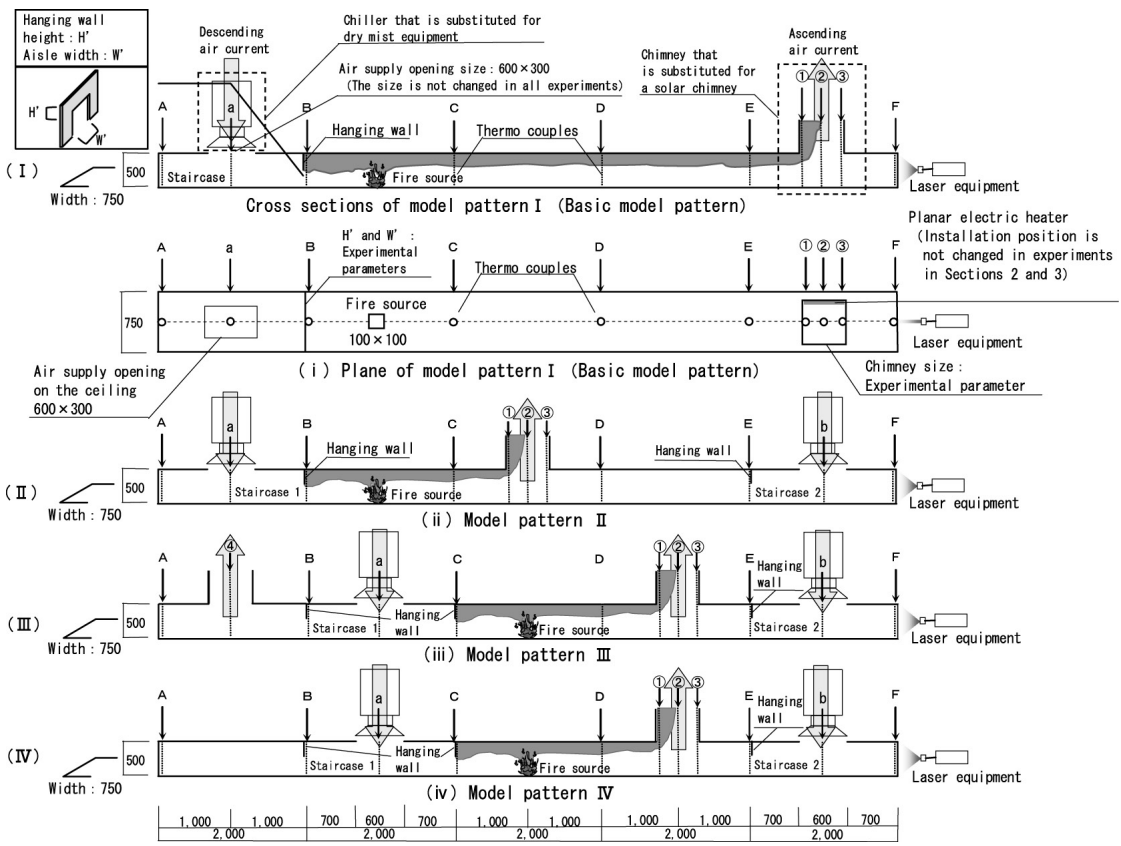

Figure 3 Details of the model pattern I IV (unit: $\mathrm{mm}$ )
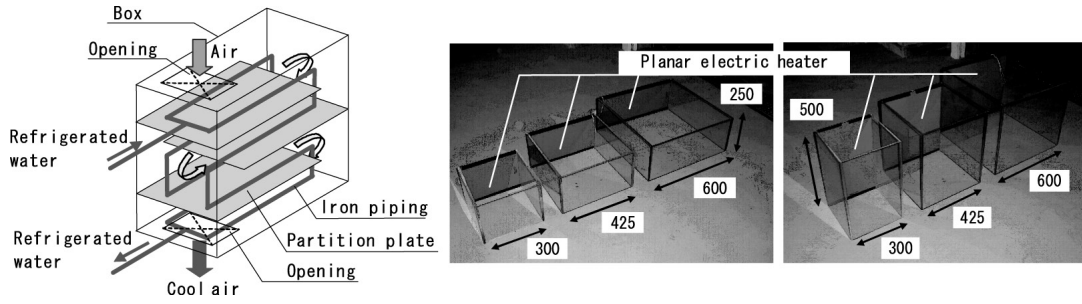

Figure 4 Internal structure of the chiller Figure 5 Various types of chimneys (unit: $\mathrm{mm}$ )

In the present experiments, the scaling laws of Equations 1 through 4 [3] were used. The ratio of physical quantities $f_{M}$ and $f_{R}$ of the model and prototype is expressed as $n(f)$.

Based on Equation 3, the heat release rate of the fire source was set to $1.68 \mathrm{~kW}$ for the model experiments in Sections 2 and 3. This is equivalent to $3 \mathrm{MW}$ for the actual scale and corresponds to the case in which approximately one-third of the combustibles in a small-scale kiosk are burnt. The fire source size was $100 \times 100 \mathrm{~mm}^{2}$, and the fuel was LP gas.

$$
\begin{aligned}
& n(t)=n(u)=n(L)^{1 / 2} \\
& n(\Delta P)=n(L) \\
& n(Q)=n(L)^{5 / 2} \\
& n(\Delta T)=n(L)^{0}
\end{aligned}
$$


$L$ : Length scale (m) $\quad \Delta P$ : Pressure rise from the reference pressure $(\mathrm{Pa})$

$t$ : Time $(\mathrm{s})$

$\Delta T:$ Temperature rise from the reference temperature $(\mathrm{K})$

$u$ : Flow velocity $(\mathrm{m} / \mathrm{s}) \quad Q:$ Heat release rate of the fire source $(\mathrm{kW})$

Based on the scaling laws in Equation 5 [3], the materials of the model should be selected to make thermal conductance to walls similar. In the experiments, acryl plates of $10 \mathrm{~mm}$ in thickness were used for the side walls and ceilings of the model and the side walls of the chimney, and plywood of $12 \mathrm{~mm}$ in thickness were used for the floor. For safety, plasterboards of $9.5 \mathrm{~mm}$ in thickness were used for the ceiling $(2,000 \times 750 \mathrm{~mm})$ directly above the fire source. Therefore, the model experiments satisfy the scaling laws as heat convection but the thermal conductance between fluid and solid are not similar (see the Appendix).

$$
n\left(\lambda_{w} \rho_{w} c_{w}\right)=n(L)^{3 / 2}
$$

$\lambda_{w}$ : Thermal conductivity of the wall $(\mathrm{kW} / \mathrm{m} \cdot \mathrm{K})$

$\rho_{w}$ : Density of the wall $\left(\mathrm{kg} / \mathrm{m}^{3}\right)$

$c_{w}$ : Specific heat of the wall $(\mathrm{kJ} / \mathrm{kg} \cdot \mathrm{K})$

\subsection{Experimental Conditions}

With the cross section and height of the solar chimney, the hanging wall height installed between the staircase and the fire room (platform), and the aisle width under the hanging wall as parameters, the experiments were conducted using the combination given in Table 2.

Table 2 Experimental conditions

\begin{tabular}{|c|c|c|c|c|c|}
\hline $\begin{array}{c}\text { Experiment } \\
\text { No. }\end{array}$ & $\begin{array}{l}\text { Model } \\
\text { pattern }\end{array}$ & $\begin{array}{c}\text { Chimney } \\
\text { section size } \\
\left(\mathrm{mm}^{2}\right)\end{array}$ & $\begin{array}{l}\text { Chimney } \\
\text { height } \\
(\mathrm{mm})\end{array}$ & $\begin{array}{l}\text { Height of the hanging wall } \\
\text { installed between } \\
\text { the staircase and the platform } \\
\text { (mm) }\end{array}$ & $\begin{array}{l}\text { Width of the aisle } \\
\text { under the hanging wall } \\
(\mathrm{mm})\end{array}$ \\
\hline $1^{*}$ & \multirow{10}{*}{ I } & \multirow{6}{*}{$425 \times 425$} & \multirow{5}{*}{500} & \multirow{3}{*}{100} & 750 \\
\hline 2 & & & & & 450 \\
\hline 3 & & & & & 300 \\
\hline 4 & & & & 150 & \multirow{2}{*}{750} \\
\hline 5 & & & & 200 & \\
\hline 6 & & & 250 & 100 & 750 \\
\hline 7 & & \multirow{2}{*}{$600 \times 600$} & 500 & \multirow[t]{2}{*}{100} & \multirow{2}{*}{750} \\
\hline 8 & & & 250 & & \\
\hline 9 & & \multirow[t]{2}{*}{$300 \times 300$} & 500 & \multirow[t]{2}{*}{100} & \multirow[t]{2}{*}{750} \\
\hline 10 & & & 250 & & \\
\hline 11 & \multirow{2}{*}{ II } & \multirow{6}{*}{$425 \times 425$} & \multirow{6}{*}{500} & 100 & 450 \\
\hline 12 & & & & 150 & 750 \\
\hline 13 & \multirow{2}{*}{ III } & & & 100 & 450 \\
\hline 14 & & & & 150 & 750 \\
\hline 15 & \multirow{2}{*}{ IV } & & & 100 & 450 \\
\hline 16 & & & & 150 & 750 \\
\hline
\end{tabular}

※ Three experiments under the same design conditions were performed in order to confirm the reproducibility of the phenomenon. 


\subsection{Experimental Method}

A fire was ignited 3,600 seconds after the activation of the chiller and the planar electric heater, and the experiment ended in 1,800 seconds. The measurement of temperature and air current velocity was started from the time of activation of the chiller and planar electric heater and was recorded every two seconds. In Figure 3, an argon ion laser beam was irradiated in a vertical sheet form at the widthwise center from the right end to visualize smoke behavior (a small amount of incense smoke was allowed into the model through the floor beside the fire source). By a visual inspection, the smoke layer thickness at each position, the smoke interruption at the hanging wall, and the smoke behavior in the horizontal long space and chimney were recorded for every experiment.

\subsection{Preliminary Study}

Before the experiments, the following items were discussed:

(1) Verification of the reproducibility of smoke behaviors under the same design conditions

In the experiments of the present study, the reproducibility of the smoke behavior in the model under the same design conditions was verified because slight differences in indoor environment, such as laboratory temperature and air current velocity in the laboratory, were expected to affect the experimental results greatly. When measurement was repeated three times under the conditions of No. 1, the measurement values approximately matched at the temperature and air current velocity measurement points shown in Figure 3. This proved the reproducibility of smoke behavior under the same conditions [4].

(2) Measurement of the air current velocity distribution at the air supply and exhaust openings

Figure 6 shows the distribution of the air current velocity measured at the exhaust openings with the Pitot tube on the right-hand side. In order to reduce the influence of measurement instrument installation on the air current behavior, the experiment was repeated three times under the same design conditions by changing the measurement position only.

Since the air current velocity at the exhaust openings has a very complicated distribution, these nine measurement points are not sufficient to investigate the volume of smoke elimination. Since the measurement error attributable to a differential manometer is approximately $0.40 \mathrm{~m} / \mathrm{s}$, an error accounts for a large ratio in the measurement results. Despite these problems, the general tendency can be investigated. However, to measure the air current velocity simultaneously at such a large number of measurement points, the exhaust openings of the model are too small. Since the cost of conduct multiple measurements under all experimental conditions is too high, the 
results are compared and discussed for different experimental conditions with the air current velocity at the center of an air supply opening, where the current behavior is comparatively easy to determine as an index of the amount of ventilation. However, the measured values are not so reliable because the hot-wire anemometer used to measure the air current velocity at the center of each air supply opening may have a measurement error of $\pm 0.10 \mathrm{~m} / \mathrm{s}$ in the measurement range of from $0.00 \mathrm{~m} / \mathrm{s}$ to $0.25 \mathrm{~m} / \mathrm{s}$.
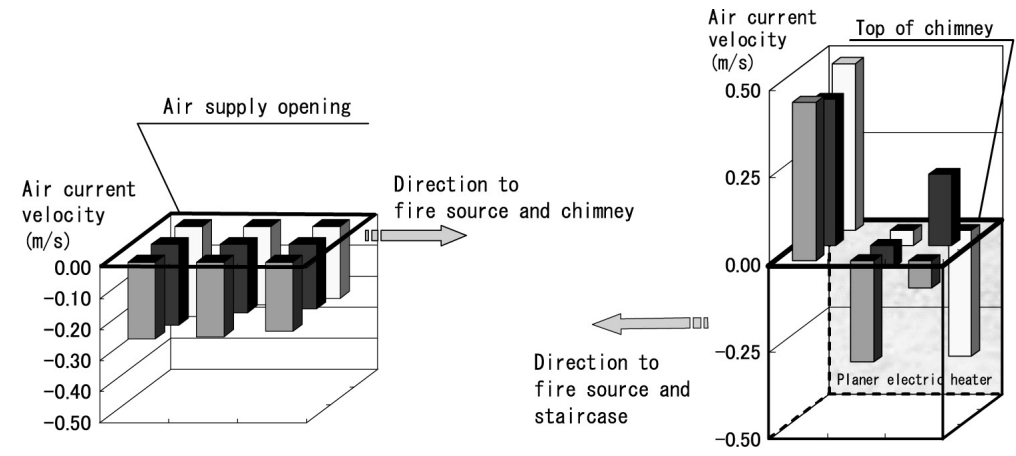

Left : Air current velocity distribution in the air supply opening (measured by hot-wire anemometer)

Right: Air current velocity distribution in the chimney top (measured by Pitot tube)

Figure 6 Measurement of air current velocity distribution in the air supply opening and the exhaust opening

\section{RESULTS OF THE BASIC MODEL EXPERIMENT AND DISCUSSION}

\subsection{Change in Chimney Cross Section and Height}

To find the size of a chimney for efficient air supply and exhaust in the experiments, measurements were conducted under experimental conditions No. 1 and No. 6 to No. 10 in Table 2, with the chimney cross section and height as parameters. Figure 7(a) shows the time series variation of the air current velocity at the center of an air supply opening, and Figures 7(b) to 7(e) show the vertical distributions of the temperature rise at position-a in the staircase and position-(1) to position-(3) in the chimney. For the measurement results, the average measured values before and after 30 seconds were plotted for the air current velocity at the center of the air supply opening because of the great time fluctuation, and the average temperature rise $\Delta T$ from the laboratory temperature at 1,740 to 1,800 seconds after ignition were plotted for vertical distributions of temperature rise at each temperature measurement position. (The same conditions are used throughout this section.)

When the air current velocity at the center of the air supply opening was compared (Figure 7(a)), no significant difference could be seen between the cases before ignition. After ignition, the air current velocity was generally lower when the chimney height 
was $250 \mathrm{~mm}$, as compared to the three cases in which the chimney height was $500 \mathrm{~mm}$, probably because it was difficult to secure the differential pressure between the inside and the outside of the chimney when the height was $250 \mathrm{~mm}$. Consequently, a back flow of outside air tended to occur at the chimney top, and a lot of smoke might flow into the staircase, as could be judged from the temperature rise at position-a in the staircase (Figure 7(b)). The back flow of outside air was judged from the visual record and the fact that the temperature rise in the chimney was great when the height from the floor was $500 \mathrm{~mm}$ or less but was small when it was over $500 \mathrm{~mm}$ in the case of $\mathrm{h}=250 \mathrm{~mm}$ (Figures 7(c) to 7(e)).

In addition, if the cross-sectional area is too large for the chimney height, a back flow of outside air may occur. This indicates that the smoke elimination performance is not always great when the chimney cross section is large.

This can be judged from the fact that the time series variation of the air current velocity at an air supply opening (Figure $7(a)$ ) is not significantly different between the chimneys of $425 \times 425 \mathrm{~mm}^{2}$ and $600 \times 600 \mathrm{~mm}^{2}$ in the three cases in which the chimney height is $500 \mathrm{~mm}$, and that the temperature rise in the upper part of the chimney is small in the case of the chimney of $600 \times 600 \mathrm{~mm}^{2}$ (Figures 7 (c) to $7($ e)).

If the exhaust opening area becomes comparatively large for the air supply opening area, the height of the natural zone is considered to become close to the exhaust opening and the pressure difference between the inside and the outside of the chimney top becomes small (outside air may tend to flow in). In addition, if the chimney cross section is great, the average temperature in the chimney after smoke inflow during a fire becomes low because smoke does not spread throughout the cross section. Therefore, sufficient pressure difference cannot be secured between the inside and the outside of the chimney when the chimney cross section is great. The amount of ventilation $V$ is proportional to $A_{c} \sqrt{\Delta P_{c}}$, where $A_{c}$ is the chimney cross-sectional area, and $\Delta P_{c}$ is the differential pressure by the density difference between outside and inside air of the chimney. Consequently, for the model of the station building assumed in the experiments, there was little difference in the amount of air supply and exhaust between the chimney cross section of $425 \times 425 \mathrm{~mm}^{2}$ and that of $600 \times 600 \mathrm{~mm}^{2}$. 


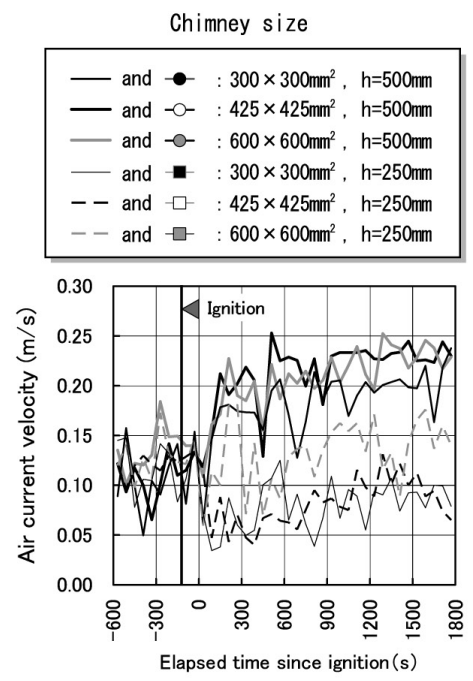

(a) Time series variation of Air current velocity at the center of the air supply opening

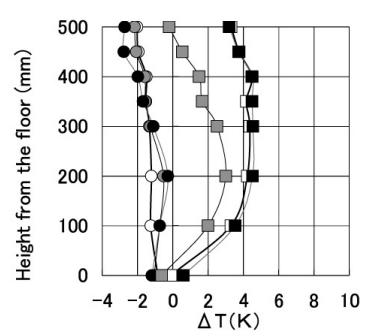

(b) Vertical distributions of temperature rise at position-a in the staircase

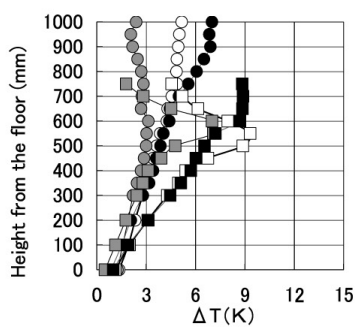

(d) Vertical distributions of temperature rise at position-(2) in the chimney

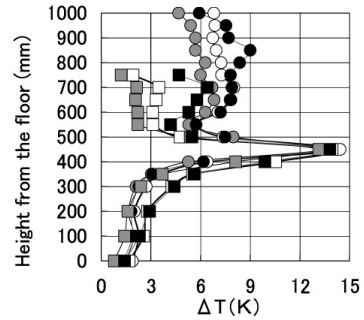

(c) Vertical distributions of temperature rise at position-(1) in the chimney

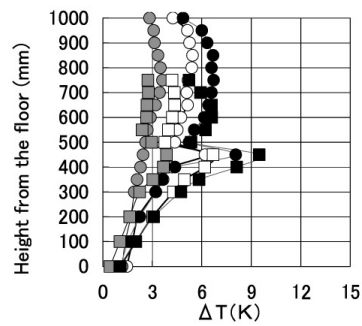

(e) Vertical distributions of temperature rise at position-(3) in the chimney

Figure 7 Comparison of chimney cross sections and heights

\subsection{Influence of Hanging Wall Height and Aisle Width on Smoke Interruption between the staircase and the fire room}

This section discusses the performance of smoke interruption between the staircase and the fire room. More specifically, this section discusses the influence of changes in the hanging wall height and/or the aisle width between the staircase and the fire room on smoke interruption by model experiment.

(1) Relationship between hanging wall size and smoke interruption

This section describes the idea of smoke interruption between the staircase and the fire room during a fire.

First, we should note that the smoke layer moves toward the staircase after the plume collides with the ceiling or flows into the bottom of the smoke layer. Here, the momentum of the smoke layer immediately before reaching the hanging wall installed between the staircase and the fire room is expressed as $\dot{m}_{s} u_{s}$ (Figure 8). If the progression of the smoke layer toward the staircase stops just under the hanging wall, the smoke flow velocity under the hanging wall becomes zero. Therefore, the momentum of the smoke layer also becomes zero. Since the transition of momentum is attributable to an external force, the working force is $\dot{m}_{s} u_{s}$ and can also be expressed as the force of the smoke layer progressing into the staircase.

Once the conditions of the dry mist sprayers and solar chimneys have been determined for this system, the force of generating air current in the station building 
(hereinafter, system force) is constant, even when the hanging wall height and the aisle width are changed. If the success or failure of smoke interruption depends on the balance of $\dot{m}_{s} u_{s}\left(=\rho_{s} u_{s}^{2} A_{s}\right)$ and the system force, reducing $A_{s}$ may satisfy the conditions of smoke interruption in the end. For a station building with this system, changing the hanging wall size, for example, does not affect the smoke layer thickness significantly because the space on the opposite side of the staircase when viewed from the fire source is open to the outside air through the solar chimney, the cross section of which is large.

If the smoke interruption between the staircase and the fire room is determined by the balance between $\dot{m}_{S} u_{s}$ and the force of the model internal air current $\dot{m}_{\text {air }} u_{\text {air }}$ generated by the system force, then $\dot{m}_{\text {air }} u_{\text {air }}$ is also expected to decrease by reducing the cross-sectional area of the aisle under the hanging wall. However, if this influence is relatively smaller than the decrease in $\dot{m}_{s} u_{s}$, then smoke interruption will be enabled by changing the hanging wall height or the aisle width.

In the following sections, we discuss the smoke interruption by changing the hanging wall height or the aisle width for the chimney of $425 \times 425 \mathrm{~mm}^{2}$ in cross section and 500 $\mathrm{mm}$ in height, having the best smoke elimination efficiency among the six, when Model pattern $\mathrm{I}$ is used and the air supply opening area is $600 \mathrm{~mm} \times 300 \mathrm{~mm}$ at a scale of $1 / 20$ (see Section 3.1 Changes in Chimney Cross Section and Height).

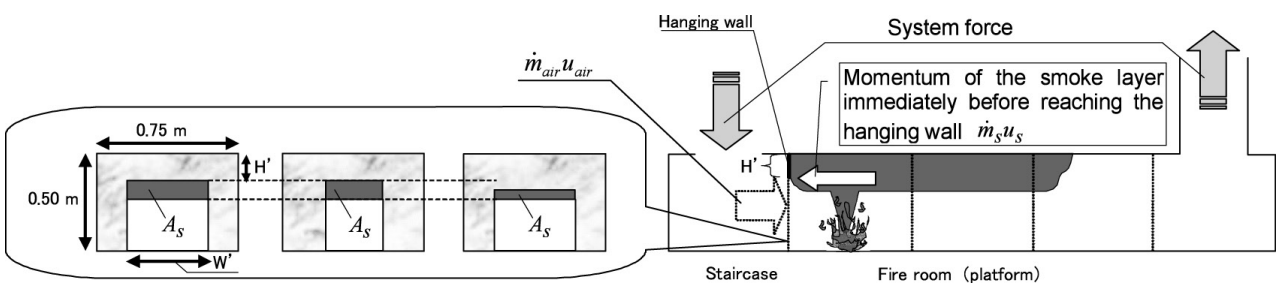

$\dot{m}_{S}$ : Mass flow rate of the smoke layer per unit time and unit cross-sectional area when passing under the hanging wall $\left(\mathrm{kg} / \mathrm{s} \cdot \mathrm{m}^{2}\right)$

$\dot{m}_{\text {air }}$ : Mass flow rate of the air current per unit time and unit cross-sectional area under the hanging wall $\left(\mathrm{kg} / \mathrm{s} \cdot \mathrm{m}^{2}\right)$

$u_{s}$ : Flow velocity of the smoke layer immediately before reaching the hanging wall $(\mathrm{m} / \mathrm{s})$

$u_{\text {air }}$ : Air current velocity under the hanging wall $(\mathrm{m} / \mathrm{s})$

$\rho_{s}$ : Density of the smoke layer $\left(\mathrm{kg} / \mathrm{m}^{3}\right)$

$H^{\prime}$ : Hanging wall height $(\mathrm{m})$

$W^{\prime}$ : Aisle width under the hanging wall (m)

$A_{s}$ : Cross-sectional area of the smoke layer under the hanging wall when the smoke layer passes under the hanging wall $\left(\mathrm{m}^{2}\right)$

Figure 8 Concept of smoke interruption between the staircase and the fire room

(2) Change of the aisle width under the hanging wall (Model pattern I)

Figure 9 shows the experimental results when the hanging wall height $H^{\prime}$ was $100 \mathrm{~mm}$ and the aisle width under the hanging wall $W^{\prime}$ was $750 \mathrm{~mm}$ (No. 1), $450 \mathrm{~mm}$ (No. 2), and 
$300 \mathrm{~mm}$ (No. 3). Under these conditions, smoke interruption could be confirmed between the staircase and the fire room only for condition No. 3, where the aisle width $W^{\prime}$ under the hanging wall was $300 \mathrm{~mm}$.

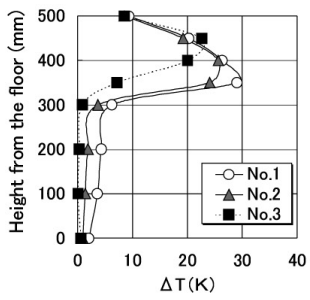

(a) Vertical distributions of temperature rise at position-B

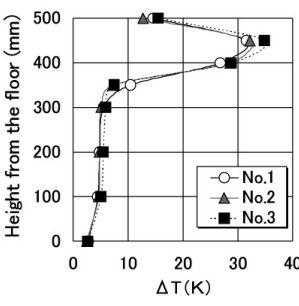

(b) Vertical distributions of temperature rise at position-D

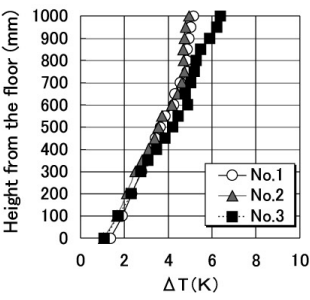

c) Vertical distributions of temperature rise at position-(2) in the chimney

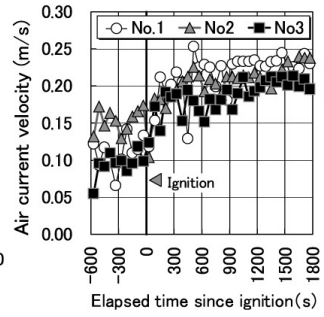

(d) Time series variation of air current velocity at the center of the air supply opening

Figure 9 Comparison by changing the aisle width under the hanging wall

At position-B and $50 \mathrm{~mm}$ from the bottom of the hanging wall (the height from the floor is $350 \mathrm{~mm}$ ), the temperature rise (Figure 9(a)) becomes greater in the order of No. 1, No. 2, and No. 3. This is probably because a collision between the smoke layer and the air current by the system force at this position suppressed the temperature rise in condition No. 3 , in which smoke interruption could be visually confirmed, but the collision was small in conditions No. 1 and No. 2, in which smoke flowed into the staircase. Below position-B $(H=0$ to $200 \mathrm{~mm})$, under the smoke layer, the temperature rise becomes greater in the order of No. 1 , No. 2 , and No. 3 . This is probably because the smoke that flowed into the staircase was moved to the fire room by the air current under conditions No. 1 and No. 2.

Above position- $\mathrm{C}$ and position-(2) in the chimney, the temperature rise (Figures 9(b) and $(c))$ is slightly greater under condition No. 3 , as compared to condition No. 1 . This is probably because the hanging wall stopped the smoke and the amount of heat moved toward the chimney instead of the staircase under condition No. 3, where the smoke interruption could be confirmed.

The air current velocity at the center of an air supply opening (Figure 9(d)) is the smallest under condition No. 3. However, since the decrease in the air supply was small and the cross sectional area of the aisle under the hanging wall was $2 / 5$ under condition No. 3, compared with condition No. 1, the air current velocity under the hanging wall and the differential pressure between the staircase and the fire room was secured.

Since the air current velocity at the center of an air supply opening and the temperature rises at position- $\mathrm{C}$ and position-(2) do not differ greatly between conditions No. 1 and No. 2, the performance of smoke interruption between the staircase and the fire room is slightly affected in the range of aisle width of from $450 \mathrm{~mm}$ to $750 \mathrm{~mm}$, but the effect on the smoke behavior in the station building does not appear to be significant. 
(3) Change of the hanging wall height (Model pattern I)

Figure 10 compares the experimental results when the aisle width under the hanging wall $W^{\prime}$ was $750 \mathrm{~mm}$ and the hanging wall height $H^{\prime}$ was $100 \mathrm{~mm}$ (No. 1), $150 \mathrm{~mm}$ (No. 2), and $200 \mathrm{~mm}$ (No. 3). Under these conditions, smoke interruption could be confirmed between the staircase and the fire room only under condition No. 5, where the hanging wall height $H^{\prime}$ was $200 \mathrm{~mm}$.

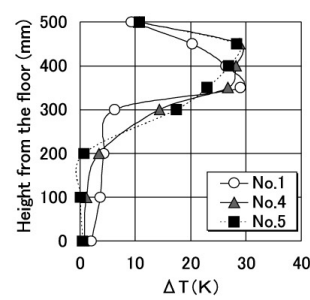

(a) Vertical distributions of temperature rise at position-B

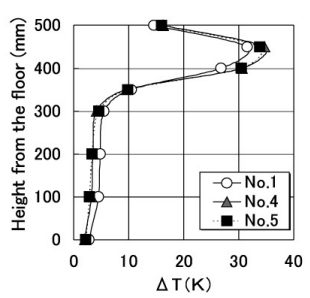

(b) Vertical distributions of temperature rise at position-D

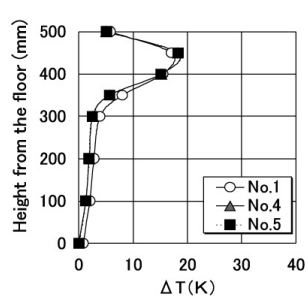

(c) Vertical distributions of temperature rise at position-(2) in the chimney

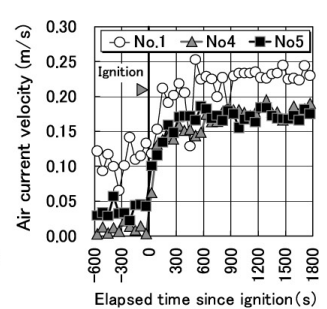

(d) Time series variation of air current velocity at the center of the air supply opening

Figure 10 Comparison by hanging wall height

The reasons for the relationships of the temperature rise below position- $\mathrm{B}$, and at position-C and position-E (Figures 10(a) to 10(c)) in each case of the experiment may be as introduced in Section 3.2(2). In the experiments, at position-E, the difference in temperature rise is smaller than that at position-C (Figure 10(c)) due to thermal loss. The temperature rises at position- $\mathrm{C}$ and position- $\mathrm{E}$ are approximately the same for conditions No. 4 and No. 5. Considering that the air current velocity at the center of an air supply opening is also approximately the same between these conditions (Figure $10(d)$ ), the boundary of smoke interruption success and failure between the staircase and the fire room may be equal to approximately the hanging wall height of $150 \mathrm{~mm}$.

According to the results of (2) and (3) in Section 3.2, this system will be able to secure the safety of a station building against a fire only if the design dimensions are appropriate. Thus far, it has been confirmed that the smoke interruption between the staircase and the fire room when the hanging wall height (aisle width) is increased (reduced) in phases to $200 \mathrm{~mm}(300 \mathrm{~mm})$. Such smoke interruption conditions as the hanging wall height or the aisle width under the hanging wall should be clarified to secure safety against a fire without using a dry mist sprayer during an intermediate season or during winter when the system force is changed. These conditions are discussed in detail in the following sections.

\subsection{Comparison of Model Patterns I to IV}

To obtain basic data concerning the smoke behavior in a station building, the previous sections have discussed Model pattern I, in which one staircase and one chimney are assumed. For an actual station building, however, at least two routes of evacuation should be secured. Here, a model experiment is conducted on Model patterns II to 
IV (see Figure 3), where two routes of evacuation are planned, in order to discuss the influence of the combination of staircases and chimneys on smoke behavior in a station building.

This section compares the smoke behavior in Model patterns I to IV for the case in which the hanging wall height $H^{\prime}$ is $100 \mathrm{~mm}$ and the aisle width under the hanging wall $W^{\prime}$ is $450 \mathrm{~mm}$, and for the case in which $H^{\prime}$ is $150 \mathrm{~mm}$ and $W^{\prime}$ is $750 \mathrm{~mm}$. In all patterns, the chimneys are $425 \times 425 \mathrm{~mm}^{2}$ and $500 \mathrm{~mm}$ in height. In each model pattern, the fire source is located at the center of the section adjacent to the staircase and its heat release rate is $1.68 \mathrm{~kW}$ as in the previous experiments.

Figure 11 shows the experimental results when $H^{\prime}$ is $100 \mathrm{~mm}$ and $W^{\prime}$ is $450 \mathrm{~mm}$ (No. 2, No. 11, No. 13, and No. 15).

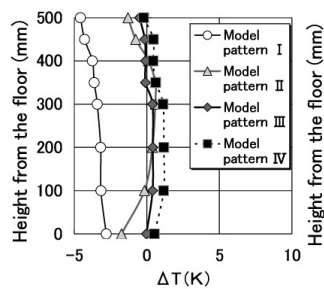

(a) Vertical distributions (b) of temperature rise at position-a in the staircase-1

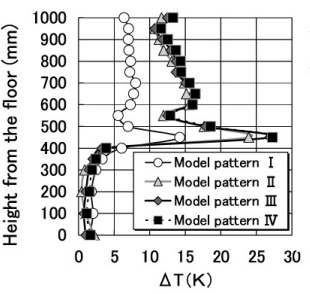

(b) Vertical distributions (c) of temperature rise at position-(1) in the chimney

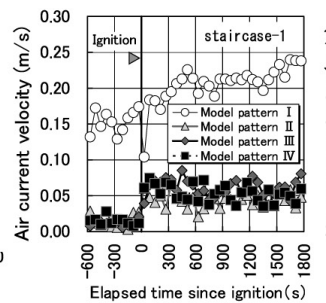

Elapsed time since ignition(s)

Time series variation of air current velocity at the center of the air supply opening-1

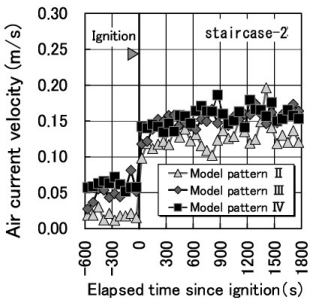

(d) Time series variation of air current velocity at the center of the air supply opening-2

Figure 11 Comparison of model patterns I to $\mathrm{IV}\left(\mathrm{H}^{\prime}=100 \mathrm{~mm}, \mathrm{~W}^{\prime}=450 \mathrm{~mm}\right)$

If the system force is approximately determined by the smoke elimination performance of a chimney, into where the smoke flows in case of a fire, Model patterns II to IV differ from Model pattern I with respect to the following:

i. Since the number of staircases is double the number of chimneys, the system force by smoke elimination from a chimney is divided into respective staircase directions. This may be disadvantageous for smoke interruption at each hanging wall position.

In Model pattern III, "the number of chimneys / the number of staircases" is the same as in Model pattern I. If high-temperature smoke flows into one chimney only and the air current behavior in the station building is controlled by the chimney during a fire, the circumstances will be the same as in Model pattern IV.

ii. Since the distance between a fire source and a chimney is short, high-temperature smoke flows into the chimney before losing much heat. Therefore, the smoke elimination performance may improve and provide an advantage to smoke interruption at each hanging wall position.

For reason ii above, the smoke flowing into a chimney in Model patterns II to IV is hotter than that in Model pattern I (Figure 11(b)). This is expected to improve the 
smoke elimination performance of the chimney. As we can see from the temperature rise distribution in staircase-1 on the fire source side (Figure 11(a)), a lot of smoke flows into staircase- 1 in Model patterns II to IV, as compared with Model pattern I. From the viewpoint of smoke interruption between the staircase and the fire room, reason i may be more influential than reason ii. In Model patterns II to IV, the air current velocity at the center of an air supply opening (Figures 11(c) and 11(d)) after ignition is smaller at Staircase 1 than at Staircase 2. This is probably because smoke flowed into staircase-1 and its buoyancy disturbed the air current of the system.

Figure 12 shows the experimental results when the hanging wall height $H^{\prime}$ is $150 \mathrm{~mm}$ and the aisle width under the hanging wall $W^{\prime}$ is $750 \mathrm{~mm}$ (No. 4, No. 12, No. 14, and No. 16). Slight smoke inflow into Staircase 1 could be confirmed in all model patterns. As shown by the temperature rise in staircase-1 (Figure 12(a)), the smoke inflow is not sufficient to increase the temperature in staircase- 1 .

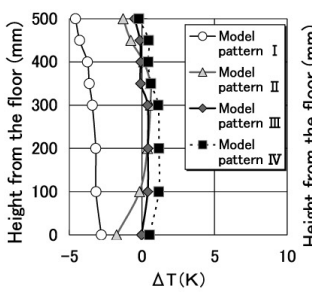

(a) Vertical distributions (b) of temperature rise at position-a in the staircase-1

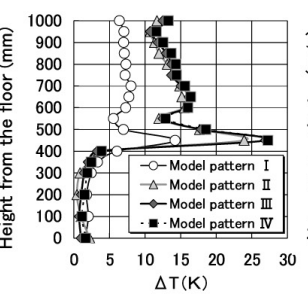

b) Vertical distributions (c) of temperature rise at position-(1) in the chimney

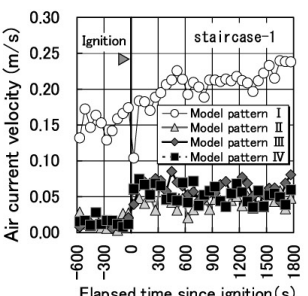

Elapsed time since ignition(s)

c) Time series variation of air current velocity at the center of the air supply opening- 1

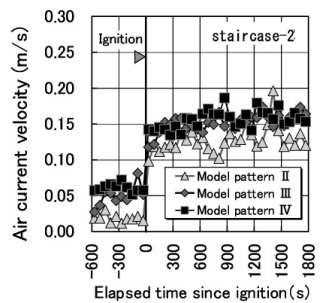

(d) Time series variation of air current velocity at the center of the air supply opening-2

Figure 12 Comparison of Model patterns I to $I V\left(H^{\prime}=150 \mathrm{~mm}, \mathrm{~W}^{\prime}=750 \mathrm{~mm}\right)$

From the air current velocity at the center of an air supply opening shown in Figures 12(c) and 12(d), the air supply from both staircases is approximately the same in Model pattern II, but is slightly greater for staircase-2 in Model patterns III and IV. This is probably because the chimney, which eliminates smoke and greatly affects the air current formation in the station building during a fire, is midway between the two staircases in Model pattern II but on the side of staircase-2 in Model patterns III and IV. If not much smoke flows into staircases during a fire, the air current behavior in a station building may be affected more by the combination of vertical shafts (chimneys and staircase) than by the fire source position.

This section focuses on the status after smoke inflow into chimneys. Since the smoke does not reach chimneys immediately after a fire, the influence of ii above may be ignored. Therefore, in Model patterns II to IV, a lot of smoke may have flowed into staircases because smoke interruption between the staircase and the fire room was difficult immediately after the occurrence of a fire, as compared with Model pattern I. Only after the smoke moves from the fire room to staircase, the system force grows as a result of reason ii. Since the formation of the smoke behavior from the fire room to the staircase during the initial phase of a fire may affect the smoke interruption after smoke 
inflow into chimneys, smoke interruption before smoke inflow into chimneys is also important. In the following sections, the conditions of smoke interruption are derived from prediction models and model experiments in the early phase of a fire (until smoke inflow into chimneys).

\section{FORMULATION OF SMOKE BEHAVIOR IN THE EARLY PHASE OF THE FIRE}

One of the purposes of the present study is to investigate the conditions of smoke interruption during a fire. Prior to the investigation, this section formulates the smoke propagation behavior during an early phase of a fire and the smoke behavior near a hanging wall after a smoke layer tip reaches the wall.

\subsection{Formulation of the Moving Velocity, Thickness, and Temperature of the Smoke Layer in the Horizontal Long Space}

Matsushita et al.[5] formulated the moving velocity of the smoke tip in horizontal long space, but this formula does not apply to the unsteady fire source considered in the present study. Here, we predict the smoke propagation behavior below the ceiling in the case of a fire in the horizontal long space (platform, concourse, etc.) as explained in the following.

The smoke propagation model is based on the following assumptions:

1) The density in the smoke layer is uniform at each time step and the layer thickness is equal between the tip of the smoke layer and the other part.

2) The pressure difference between smoke layer and the ambient air depends on the density difference only. The pressure difference at height $h$ from the bottom of the smoke layer can be expressed as follows:

$$
\Delta P=\Delta \rho g h
$$

3) The relationship between the pressure difference $\Delta \mathrm{P}_{s}$ from the ambient air at the tip of the smoke layer and the smoke tip moving velocity $u_{s l}$ can be expressed as Equation 7 . Both the pressure difference between the smoke layer and the air layer and the smoke tip moving velocity are zero at the bottom height of the smoke layer.

$$
C_{1} \rho_{s} u_{s 1}^{2}=\Delta P_{s}\left(\mathrm{C}_{1}: \text { Proportional constant }\right)
$$

4) The transition of the wall surface temperature $T w$ is not considered, and the temperature is assumed to be equal to the ambient air temperature $T_{\infty}$.

From Equations 6 and 7, the moving velocity of the smoke tip at arbitrary height $h$ from the bottom of the smoke layer is:

$$
u_{s 1}=\left(\frac{\Delta \rho_{1} g h}{C_{1} \rho_{s 1}}\right)^{1 / 2}
$$


At the smoke tip, the moving velocity has a vertical distribution. The volumetric flow rate at the tip $Q_{s 1}$ (Equation 9), calculated from the smoke layer thickness $h_{s l}$, the flow width $B_{s}$, and the moving velocity $u_{s l}$, is divided by $h_{\mathrm{s} 1}$ and $B_{\mathrm{s}}$ to determine the average moving velocity $\bar{u}_{s l}$ (Equation 10). This equation is used for prediction in the present study.

$$
\begin{aligned}
& Q_{s 1}=B_{s} \int_{0}^{h_{s 1}} u_{s 1} d h=\frac{2}{3} B_{s}\left(\frac{\Delta \rho_{1} g}{C_{1} \rho_{s 1}}\right)^{1 / 2} h_{s 1}^{3 / 2} \\
& \bar{u}_{s 1}=\frac{Q_{s 1}}{B_{s} h_{s 1}}=\left(\frac{2}{3}\right)\left(\frac{\Delta \rho_{1} g}{C_{1} \rho_{s 1}}\right)^{1 / 2} h_{s 1}^{1 / 2}
\end{aligned}
$$

From the heat conservation equation (Equation 11) and the mass conservation equation (Equation 12), an equation for the average smoke layer temperature change considering the thermal loss to a wall can be obtained (Equation 13). Heat exchange by radiation is not considered in Equation 11.

$$
\begin{aligned}
& \frac{d\left\{C_{p}\left(\rho_{s 1} V_{s 1}\right) T_{s 1}\right\}}{d t}=C_{p} \rho_{0} Q_{0} T_{0}-\alpha A_{s 1}\left(T_{s 1}-T_{w}\right) \\
& \frac{d\left(\rho_{s 1} V_{1 s}\right)}{d t}=\rho_{0} Q_{0} \\
& C_{p}\left(\rho_{s 1} V_{s 1}\right) \frac{d T_{s 1}}{d t}=C_{p} \rho_{0} Q_{0}\left(T_{0}-T_{s 1}\right)-\alpha A_{s 1}\left(T_{s 1}-T_{w}\right)
\end{aligned}
$$

To predict the smoke tip moving velocity in the present study, the initial conditions shown in Figure 13 are set as the conditions for the model experiments described in Section 5. By forward calculation, at every time step, the transition of the average smoke layer temperature is calculated from Equation 13 and the transition of the distance from the central axis of the fire source to the smoke tip is calculated by sequentially adding the moving distance $\left(\bar{u}_{s 1}\right.$ (Equation 10) $\times$ fine time $\left.\Delta \mathrm{t}\right)$. The smoke layer thickness is calculated at the every time step, compensating for the difference between "the mass flow rate from the plume into the smoke layer" and "the mass increase in the smoke layer + the mass flow rate at the smoke tip" (Equation 14, Figure 14).

$$
h_{s 1(t+1)}=\frac{\rho_{0} Q_{0} \cdot \Delta t-\left(d \rho_{s 1} V_{s 1} / d t\right) \Delta t-\left(\bar{u}_{s 1} \cdot \Delta t\right) B_{s} h_{s 1(t)} \rho_{s 1}}{\left\{X_{1}+\left(\bar{u}_{s 1} \cdot \Delta t\right)\right\} B_{s} \rho_{s 1}}+h_{s 1(t)}
$$

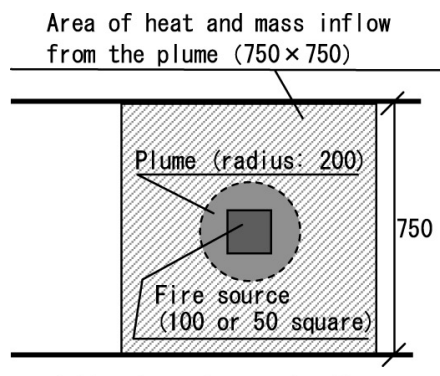

a) Top-down view at the fire source

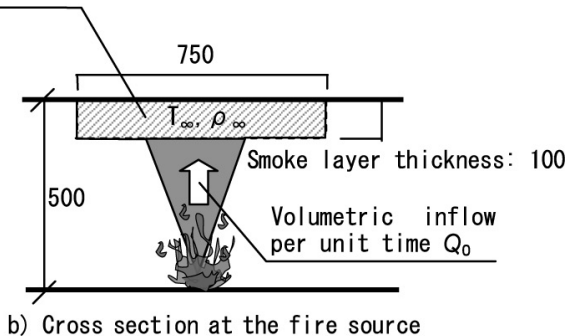

b) Cross section at the fire source

Figure 13 Initial conditions of calculation (units: $\mathrm{mm}$ ) 


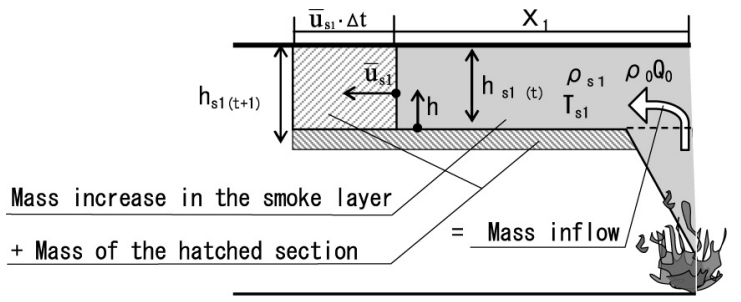

Figure 14 Model of smoke propagation in the early phase of a fire

\subsection{Calculation of Heat and Mass Inflow from the Plume into the Smoke Layer}

For the model experiments in the next section, the four types of fire sources shown in Table 3 are set. However, since the set heat release rate of each fire source is not attained immediately after ignition and the fire source becomes unsteady, the plume behavior based on the set heat release rate cannot be used for calculation. By using cone calorimeter equipment (ISO 5660), the heat release rate of each fire source was measured by the oxygen consumption method (Figure 15). The experiment was repeated several times by fire source conditions. Since the measured values approximately matched, Figure 15 shows their average values.

Table 3 Experimental conditions

\begin{tabular}{|c|c|c|c|c|}
\hline No. & $\begin{array}{c}\text { Fire source } \\
\text { size }\left(\mathrm{mm}^{2}\right)\end{array}$ & $\begin{array}{c}\text { Set gas } \\
\text { flow rate } \\
(\ell / \mathrm{min})\end{array}$ & $\begin{array}{c}\text { Set heat } \\
\text { release rate } \\
\mathrm{Q}(\mathrm{kW})\end{array}$ & $\begin{array}{c}\text { Heat release rate } \\
\text { converted into } \\
\text { real size }(\mathrm{MW})\end{array}$ \\
\hline 1 & $100 \times 100$ & 1.02 & 1.68 & 3 \\
2 & $100 \times 100$ & 0.68 & 1.12 & 2 \\
3 & $50 \times 50$ & 0.68 & 1.12 & 2 \\
4 & $50 \times 50$ & 0.34 & 0.56 & 1 \\
\hline
\end{tabular}

※The heat release rate was calculated with the total amount of heat from LP gas as $23,673 \mathrm{kcal} / \mathrm{m}^{3}$

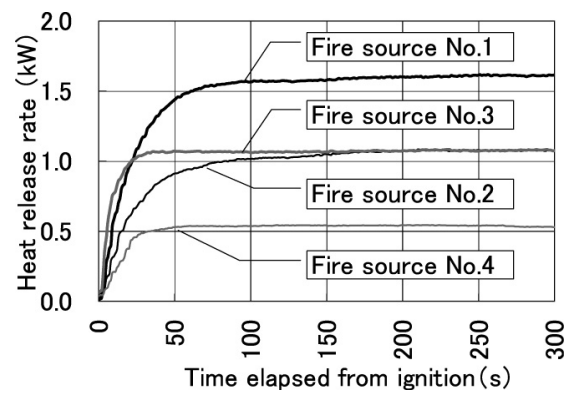

Figure15 Time series variation of H.R.R. 
The heat and mass inflow from the plume into the bottom of the smoke layer is calculated from the average measurement of the heat release rate based on the following assumptions:

5) Air entrainment from the side is not limited because the experimental model is $750 \mathrm{~mm}$ in width (actual size: $15 \mathrm{~m}$ ), which is sufficiently large for the fire source. In addition, the combustion behavior (the flame and plume behavior and the height of virtual-point heat source) in the free space is applicable without considering the influence of the ceiling.

6) The horizontal distributions of in-plume temperature rise and vertical flow velocity conform to normalized distributions.

For the flame and plume characteristics, the experimental formula of Zukoski, Thomas, et al. [6] is adopted and the temperature rise and the vertical flow velocity at an arbitrary height $z^{\prime}$ on the central axis of the plume is calculated.

$$
\begin{array}{lll}
\frac{b_{P}}{z^{\prime}}=0.13 & (15) & \frac{\Delta T_{0}}{T_{\infty}}=9.1 Q_{Z^{\prime}}^{* 2 / 3} \\
\frac{w_{0}}{\sqrt{g z^{\prime}}}=3.9 Q_{Z^{\prime}}^{* 1 / 3} & \text { (17) } & z_{0}=1.5 \sqrt{A_{f}}
\end{array}
$$

Where, $Q_{Z^{\prime}}^{*} \equiv \frac{Q}{\rho_{\infty} C_{P} T_{\infty} \sqrt{g} z^{\prime 5 / 2}}$

From the assumption of 6), the temperature and flow velocity at the point ( $\left.z^{\prime}, r\right)$, where $z^{\prime}$ is the height from the virtual-point heat source $\left(=z+z_{0}\right)$ and $r$ is the horizontal distance from the central axis of the fire source, were calculated as follows [6]:

- Temperature rise: $\Delta \mathrm{T}\left(z^{\prime}, r\right)\left(=T\left(z^{\prime}, r\right)-T_{\infty}\right)$

$$
\frac{\Delta T\left(z^{\prime}, r\right)}{\Delta T_{0}\left(z^{\prime}\right)}=\exp \left[-\beta^{2}\left(\frac{r}{b_{p}}\right)^{2}\right]\left(\text { Where, } \beta_{2}=0.9\right)
$$

- Axial flow velocity: $w\left(z^{\prime}, r\right)$

$$
\frac{w\left(z^{\prime}, r\right)}{w_{0}\left(z^{\prime}\right)}=\exp \left[-\left(\frac{r}{b_{p}}\right)^{2}\right]
$$

From the temperature rise $\Delta \mathrm{T}\left(z^{\prime}, r\right)$ and flow velocity $w\left(z^{\prime}, r\right)$ at height $z^{\prime}\left(=z+z_{0}\right)$ from the virtual-point heat source to the bottom of the smoke layer at every time step, the mass inflow $2 \rho_{0} Q_{0}\left(z^{\prime}\right)$ from the plume into the smoke layer can be expressed as follows:

$$
2 \rho_{o} Q_{0}\left(z^{\prime}\right)=\int_{0}^{r}\left[\frac{353}{\Delta T\left(z^{\prime}, r_{n}\right)+T_{\infty}}\right] \cdot\left[w\left(z^{\prime}, r_{n}\right) \pi r_{n}^{2}-w\left(z^{\prime}, r_{n}\right) \pi r_{n-1}^{2}\right] d r
$$

Where, $r_{\mathrm{n}}=r_{\mathrm{n}-1}+\Delta r$ 
The heat inflow $2 C_{p} \rho_{0} Q_{0} T_{0}\left(z^{\prime}\right)$ from the plume into the smoke layer can be expressed as follows:

$$
2 C_{p} \rho_{0} Q_{0} T_{0}\left(z^{\prime}\right)=\int_{0}^{r} C_{p}\left[\frac{353}{\Delta T\left(z^{\prime}, r_{n}\right)+T_{\infty}}\right] \cdot\left[w\left(z^{\prime}, r_{n}\right) \pi r_{n}^{2}-w\left(z^{\prime}, r_{n}\right) \pi r_{n-1}^{2}\right] \cdot\left[\Delta T\left(z^{\prime}, r_{n}\right)+T_{\infty}\right] d r
$$

At the position of horizontal distance $r=0.2 \mathrm{~m}$ from the central axis of the fire source, the calculated values of $\Delta T\left(z^{\prime}, r\right)$ and $w\left(z^{\prime}, r\right)$ were approximately zero for all fire sources listed in Table 3. Therefore, the range of integration was set to $0 \leqq r \leqq 0.2$. The smoke behavior model in the present study is based on the assumption that approximately half of the mass and heat inflow from the plume into the smoke layer is apportioned to the smoke layer on the staircase side.

\subsection{Formulation of the Smoke Behavior after the Smoke Tip Reaches the Hanging Wall}

This section models the smoke behavior after reaching the hanging wall. For this modeling, the area of the smoke layer at the time when the smoke tip reaches the hanging wall is defined as the upper part of the smoke layer, and the smoke layer flowing below the upper part of the smoke layer after reaching the hanging wall is defined as the lower part of the smoke layer.

The following assumptions are added to assumptions 1) to 6) in the previous sections:

7) After the smoke tip reaches the hanging wall, the upper part of the smoke layer thickness does not vary.

8) After the lower part of the smoke tip reaches the fire source, the smoke layer thickness does not vary. The mass is then balanced in the smoke layer between the fire source and the hanging wall (Equation 23, Figure 17).

$$
\rho_{0} Q_{0}=\frac{d\left(\rho_{s 1} V_{s 1}\right)}{d t}+\frac{d\left(\rho_{s 2} V_{s 2}\right)}{d t}+M_{\text {out }} \quad\left(V_{s 1}, V_{s 2}: \text { fixed }\right)
$$

According to the above assumptions, the initial conditions shown in Figure 16 are set for calculation after the smoke layer reaches the hanging wall. Using Equation 26 obtained from the heat conservation equation (Equation 24) and the mass conservation equation (Equation 25), the temperature rise at every time step in the upper part of the smoke layer is calculated. Using the temperature of the upper part of the smoke layer and Equation 25, the mass and heat inflow from the upper part of the smoke layer into the lower part of the smoke layer is calculated at every time step. With the mass and heat inflow, the transitions in temperature of the lower part of the smoke layer $T_{s 2}$, the moving velocity toward the fire source $\bar{u}_{s 2}$, and the smoke layer thickness $H_{s}$ are calculated in the same way as the smoke propagation model in Section 4.1. In the calculation, no mixing between the upper part of the smoke layer and the lower part of the smoke layer is considered. 


$$
\begin{aligned}
& C_{p} \rho_{0} Q_{0} T_{0}=\frac{d\left\{C_{p}\left(\rho_{s 1} V_{s 1}\right) T_{s 1}\right\}}{d t}+C_{p} \rho_{s 1} Q_{s 1} T_{s 1}+\alpha A_{s 1}\left(T_{s 1}-T_{w}\right) \\
& \rho_{0} Q_{0}=\frac{d\left(\rho_{s 1} V_{s 1}\right)}{d t}+\rho_{s 1} Q_{s 1} \\
& C_{p}\left(\rho_{s 1} V_{s 1}\right) \frac{d T_{s 1}}{d t}=C_{p} \rho_{0} Q_{0}\left(T_{0}-T_{s 1}\right)-\alpha A_{s 1}\left(T_{s 1}-T_{w}\right)
\end{aligned}
$$

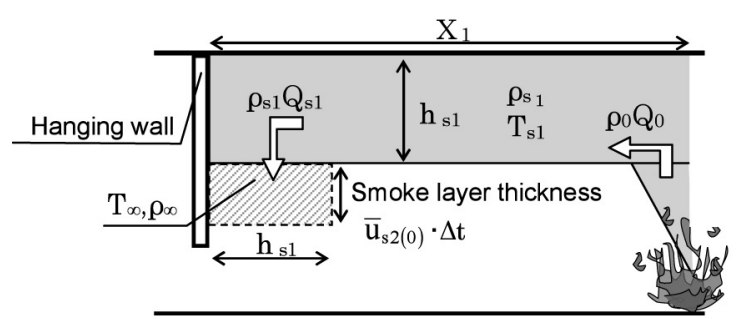

Where, $\overline{\mathrm{u}}_{\mathrm{s} 2(0)}: \overline{\mathrm{u}}_{\mathrm{s} 1}$ when the smoke layer tip has reached the hanging wall

Figure 16 Initial conditions of calculation after reaching the hanging wall
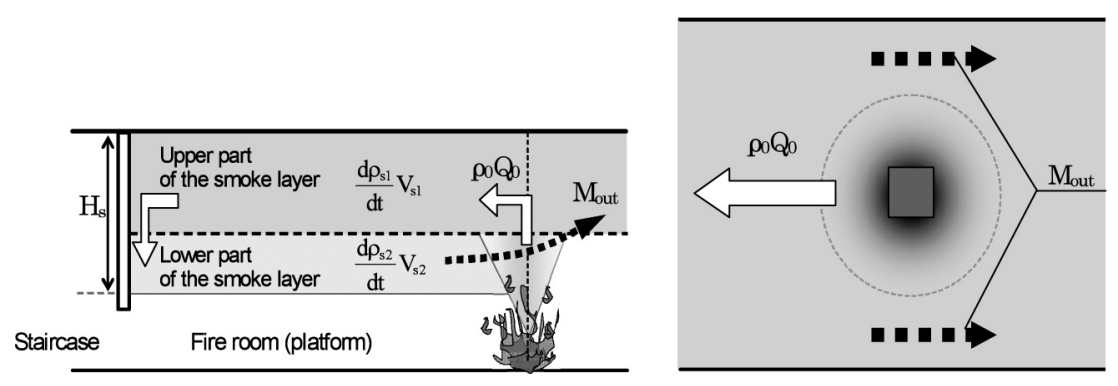

Figure 17 Balance of mass in the smoke layer (Assumption 8)

\section{OUTLINE OF MODEL EXPERIMENT OF SMOKE INTERRUPTION BETWEEN THE STAIRCASE AND THE FIRE ROOM}

\subsection{Outline of the Model and Measurement Positions}

For the model experiment in Sections 2 and 3, the chiller above the staircase and the chimney with a planar electric heater formed air current in the model. In this section, the experiment is conducted with the pre-ignition air current velocity as one of the experimental parameters. For easy adjustment of the air current velocity, the chimney height was set to $1,000 \mathrm{~mm}$ and a planar electric heater was installed on each of the four side walls (lower half only) inside the chimney (cross section: $425 \times 425 \mathrm{~mm}^{2}$ ). In addition, no chiller was installed above the staircase. 
In order to confirm the smoke tip moving velocity, the smoke inflow into the staircase, the smoke layer temperature, the ventilation (smoke elimination) performance, and the air current velocity under the hanging wall, thermocouples and anemometers were installed as indicated in Figure 18.

At the position of each thermocouple, the reach of the smoke tip and the smoke inflow into the staircase were judged when the thermocouple temperature has increased 0.2 (K) or more from the average measured value for 60 seconds before ignition.

In order to calculate the air buoyancy in a chimney, a total of 75 thermocouples were installed inside the chimney at 100-mm intervals from a height of $50 \mathrm{~mm}$ from the floor in the vertical direction and at positions (1) through (5) in Figure 18 in the horizontal direction. In Figure 18, each area surrounded by dotted lines is equal. The average density on the horizontal cross section in the chimney was the average of the calculated densities based on the temperature measurements of the thermocouples from (1) through (5).

In order to confirm the amount of ventilation before ignition, based on JIS B 8330, the cross section at the lengthwise center of the model was divided into 20 equal virtual areas and the air current velocity at the center of each area was measured. (In this experiment, however, the air current velocity was measured only at the 12 points shown in Figure 18 because the cross section was symmetric along the widthwise center.)

In the experiments, four types of fire sources shown in Table 3 were used. The fire source position could be changed to a), b), and c) shown in Figure 18.

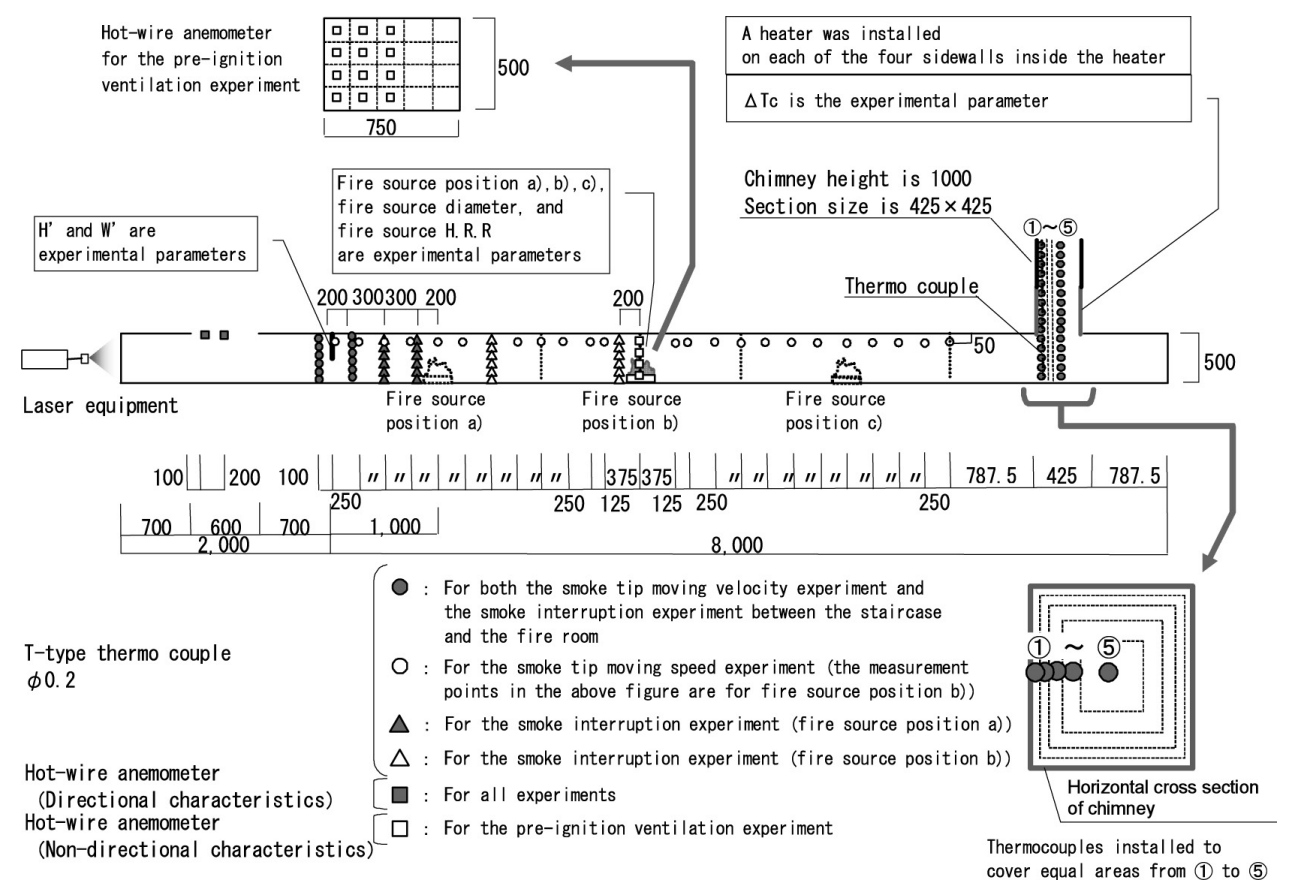

Figure 18 Outline of the model and measurement positions (unit: $\mathrm{mm}$ ) 


\subsection{Experimental conditions}

The fire source position, diameter $D$, the heat release rate $Q$, the hanging wall height $H^{\prime}$, the aisle width under the hanging wall $W^{\prime}$, and the temperature rise of planar electric heaters in the chimney $\Delta T_{c}$ were set as parameters. The experiments were conducted under the conditions given in Table 4.

Table 4 Experimental conditions

\begin{tabular}{|c|c|c|c|c|c|}
\hline Experiment type & $\begin{array}{c}\text { Fire source } \\
\text { position }\end{array}$ & $\begin{array}{c}\text { Fire source } \\
\text { No. }\end{array}$ & H $^{\prime}(\mathrm{mm})$ & W ' (mm) & $\Delta$ Tc (K) \\
\hline Smoke tip moving velocity & b), c) & $1 \sim 4$ & 150 & 750 & $0,20,40,60$ \\
\hline Smoke interruption & a), b) , c) & 1 & 0 to $400(50$ steps) & 300 to 750 (150 steps) & $0,20,40,60$ \\
\hline Pre-ignition ventilation amount & - & - & 0,150 & 300 to 750 (150 steps) & $0,20,40,60$ \\
\hline
\end{tabular}

\subsection{Experimental Method}

In the experiments of the smoke tip moving velocity and the smoke interruption between the staircase and the fire room, a fire was ignited 5,400 seconds after the activation of the planar electric heater and the experiments were completed 300 seconds later. The temperature and air current velocity were measured from the activation of the planar electric heaters and were recorded at one-second intervals. To visualize the smoke behavior, an argon ion laser beam was irradiated in vertical sheet form at the widthwise center from the left end, as shown in Figure 18.

In the experiments of the pre-ignition ventilation amount, the air current velocity measurement was started 7,200 seconds after activation of the planar electric heaters. The air current velocity was measured at each measurement position at 5-second intervals for 600 seconds. To suppress the turbulence of the air current in the model, only one or two hot-wire anemometers were installed, and only the measurement positions were changed each time.

To calculate the amount of ventilation per unit time from the measurement values, the measurements in the latter 300-second period at each position were averaged to determine the air current velocity by considering the turbulence of the air current accompanying the movement of measurement equipment.

To visualize the smoke movement as required, as a smoke generator, a smoke element was placed inside the model from the floor beside the fire source at ignition and the flow of smoke was recorded using a video camera. The next section does not deal with the temperature and velocity measurement from the experiments using a smoke element.

\section{EXPERIMENTAL RESULTS AND DISCUSSION}

Figure 19 shows the experimental results for the transition of the smoke tip position and the calculation results using a smoke propagation model when the fire sources 
given in Table 3 are used under the conditions of $\Delta \mathrm{Tc}=0(\mathrm{~K})$ and fire source position $\mathrm{b})$. The plot colors indicate the directions of position change of the smoke tip in a single experiment (gray: toward the staircase, white: toward the chimney) and the plot types indicate the results under the same design condition. Proportional constant $C_{1}$ in Equation 10 was calculated under each fire source condition by the least squares method because it should be determined from experimental results. Here, the average $C_{1}$ in each experiment $\left(C_{\text {lave }}=0.69\right)$ was used for analysis.

Even when the fire source diameter and the heat release rate were different, the calculated smoke tip velocity matched the experimental results well. The calculated smoke layer thickness was almost equal to the experimental result. Therefore, the smoke propagation model in the early phase of a fire reproduced the experimental result well.

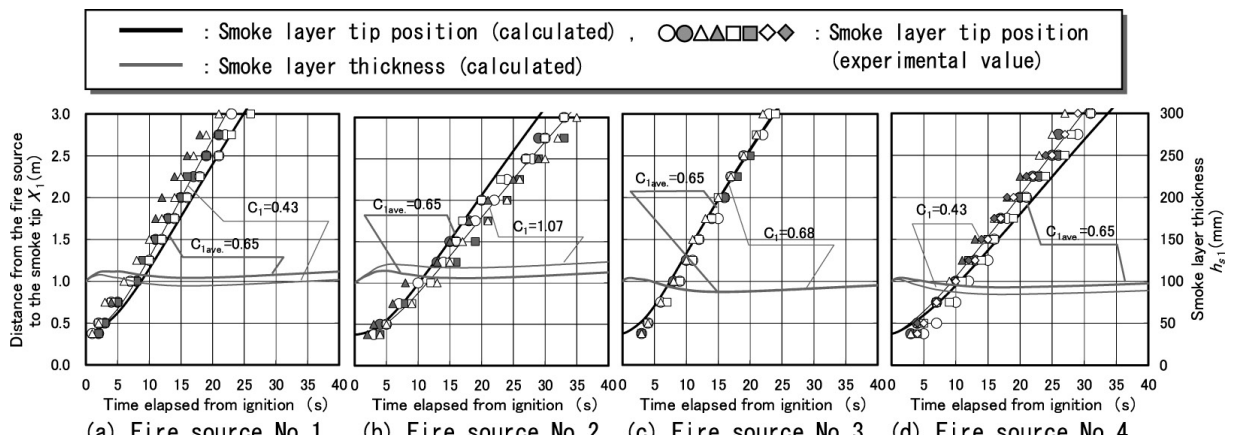

$\begin{array}{llll}\text { (a) Fire source No.1 } & \text { (b) Fire source No.2 } & \text { (c) Fire source No. } 3 & \text { (d) Fire source No. } 4\end{array}$

Figure 19 Transition of smoke tip position (left axis) and smoke layer thickness (right axis) under $\Delta T c=0(K)$

The calculated and experimental results are then compared with respect to the smoke behavior after the smoke tip reaches the hanging wall.

Under the conditions of fire source No. $1, \Delta \mathrm{Tc}=0(\mathrm{~K})$, and fire source position a), the smoke layer thickness after reaching the hanging wall was approximately $250 \mathrm{~mm}$ to $300 \mathrm{~mm}$ from the visualized experimental records (Figure 20). The smoke layer thickness $H^{\prime}$ inferred from the temperature rise in the staircase in each smoke interruption experiment was also from $250 \mathrm{~mm}$ to $300 \mathrm{~mm}$. However, the smoke layer thickness after reaching the hanging wall, as calculated from the smoke behavior model, was approximately $220 \mathrm{~mm}$ (where, $C_{2}=C_{\text {lave. }}=0.69$ ) (Figure 21).

Visualization in the experiment clarified the mixture of smoke and air layers and the diffusion of smoke immediately after the smoke tip reached the hanging wall. Since these phenomena may have greatly lowered the smoke layer, their influence should also be considered in the smoke behavior model. Considering the heat transfer by mixing and diffusion after the smoke tip reaches the hanging wall, the heat transfer between the lower part of the smoke layer and the air layer was expressed simply as $\alpha^{\prime} A_{s 3}\left(T_{s 2}-T_{\infty}\right)$ and was added to the heat conservation equation in the present study. Three types of calculations were performed: $\alpha^{\prime}=0$ (no thermal loss between the lower part of the smoke layer and the air layer), $\alpha^{\prime}=\alpha$ (thermal loss No. 1), and $\alpha^{\prime}=2 \alpha$ (thermal loss No. 2). If the 
heat transfer between the lower part of the smoke layer and the air layer is considered, both the smoke layer thickness (Figure 21) and the temperature in the smoke layer (Figure 22(a)) matched the experimental results well (the results for fire source No. 2 to No. 4 also matched the experimental results well if the heat transfer between the lower part of the smoke layer and the air layer was considered (Figures 22(b) to 22(d))).
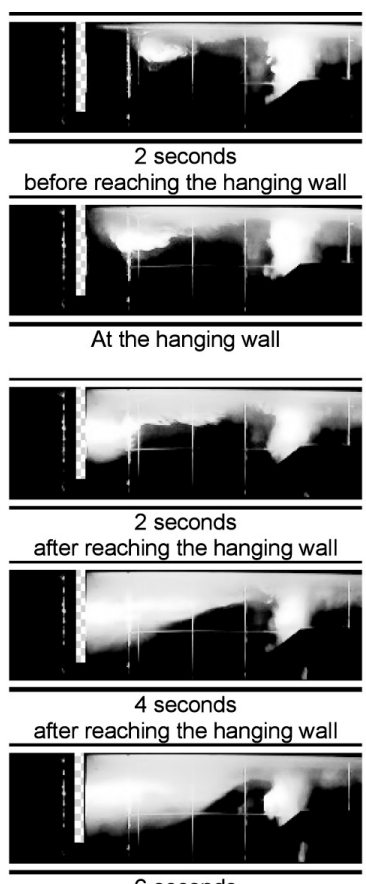

6 seconds

after reaching the hanging wall

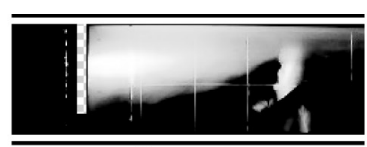

8 seconds

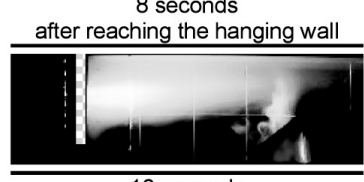

10 seconds

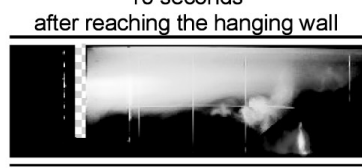

12 seconds

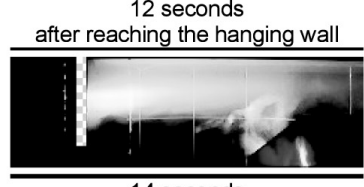

14 seconds

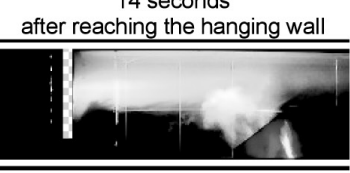

16 seconds

after reaching the hanging wall

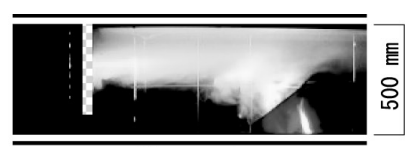

18 seconds

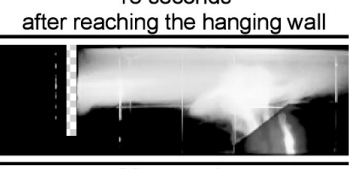

20 seconds

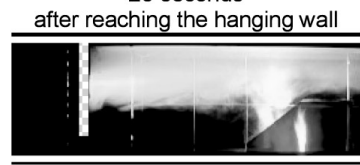

30 seconds

after reaching the hanging wall

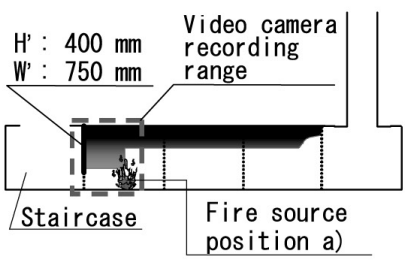

position a)

Figure 20 Smoke behavior after reaching the hanging wall (visualized record)

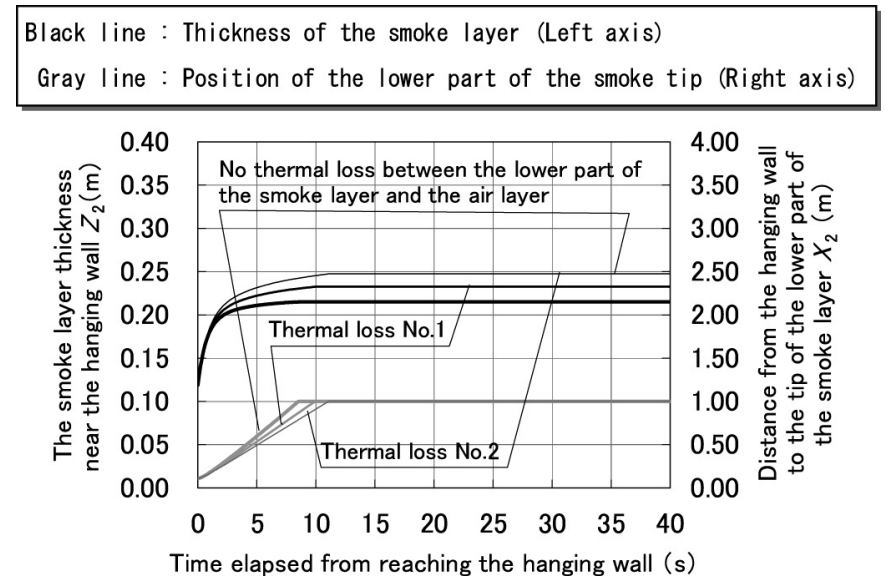

Figure 21 Calculated smoke layer thickness after reaching the hanging wall under the conditions of $\Delta T c=0(K)$, fire source No. 1, and fire source position a) 


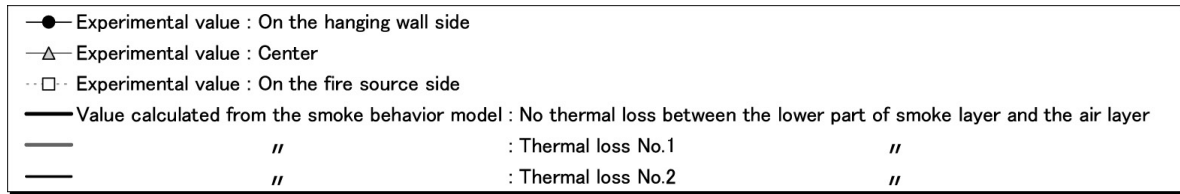

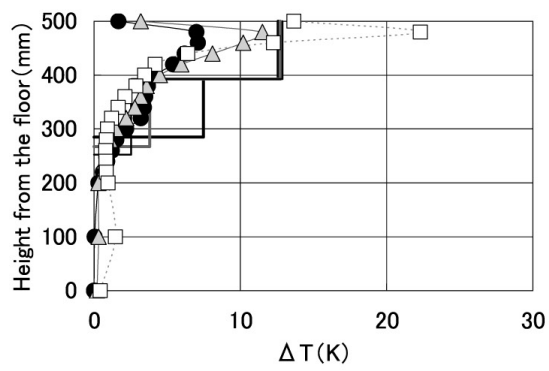

(a) Fire source No. 1

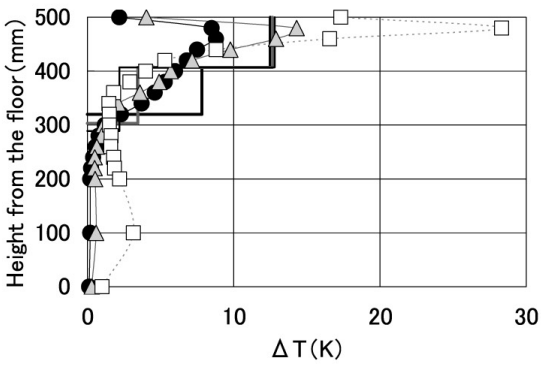

(c) Fire source No. 3

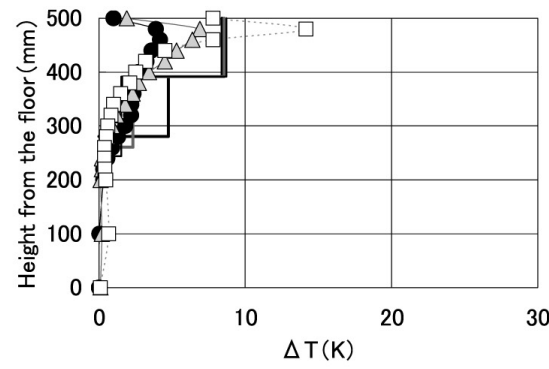

(b) Fire source No. 2

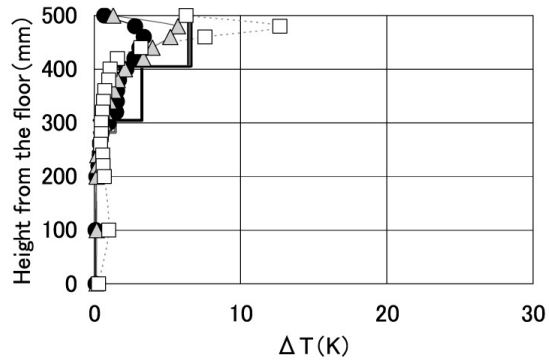

(d) Fire source No. 4

Figure 22 Comparison of the smoke layer height and temperature between the fire source and the hanging wall 30 seconds after ignition

(Fire source position a), $H^{\prime}=400 \mathrm{~mm}, W^{\prime}=750 \mathrm{~mm}, \Delta T c=0 \mathrm{~K}$ )

For smoke interruption when the hanging wall height $H^{\prime}$ is smaller than the smoke layer thickness $H_{s}$, air current formed by a chimney is necessary (Figure 23). Regarding the smoke interruption between the staircase and the fire room, two concepts were introduced in Section 3.2(1). By considering that the balance of the air current force and the smoke progressing force determines smoke interruption, we calculate the air current velocity under the hanging wall $u_{\text {air }}$ that permits smoke interruption (Figure 24). Since the air current grows after the smoke inflow into a chimney and assists smoke interruption, $u_{\text {air }}$ was calculated until the smoke flowed into the chimney and the thickness of the smoke layer (the lower part of the smoke layer) became stable. Even in the experiments, the smoke inflow into a staircase several minutes after ignition could not be confirmed. 


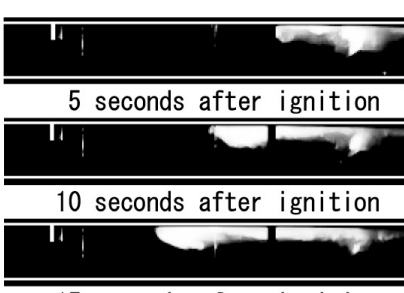

15 seconds after ignition

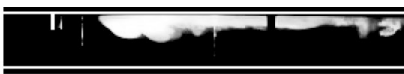

20 seconds after ignition

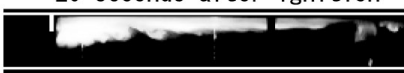

25 seconds after ignition

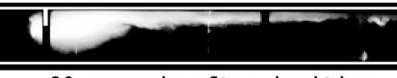

30 seconds after ignition

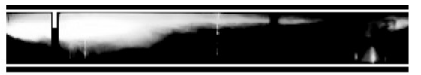

35 seconds after ignition

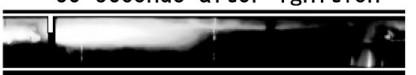

40 seconds after ignition

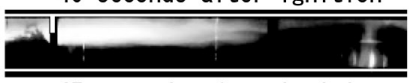

45 seconds after ignition

$\Delta \mathrm{Tc}=0(\mathrm{~K})$ Fire source position $\mathrm{b})$, Fire source $\mathrm{No}^{\prime}, \mathrm{H}^{\prime}=150 \mathrm{~mm}, \mathrm{~W}^{\prime}=750 \mathrm{~mm}$

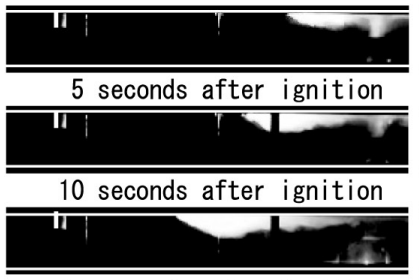

15 seconds after ignition

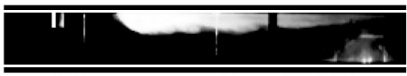

20 seconds after ignition
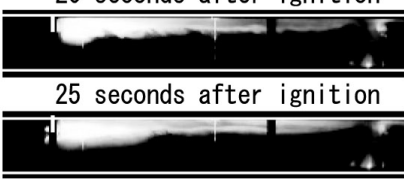

30 seconds after ignition

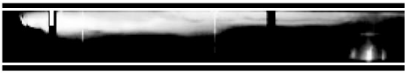

35 seconds after ignition

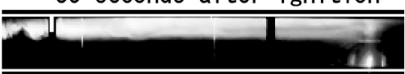

40 seconds after ignition

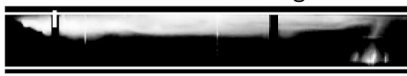

45 seconds after ignition

$\Delta \mathrm{Tc}=20(\mathrm{~K})$ Fire source position b), Fire source No. 1, $H^{\prime}=150 \mathrm{~mm}, W^{\prime}=750 \mathrm{~mm}$

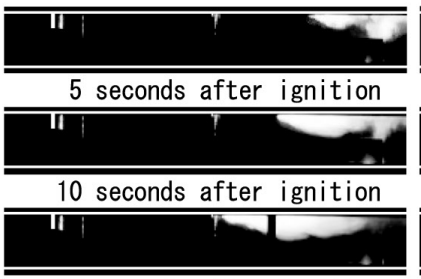

15 seconds after ignition

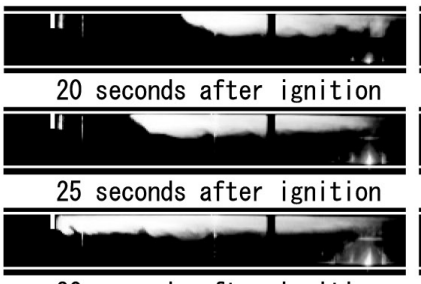

30 seconds after ignition

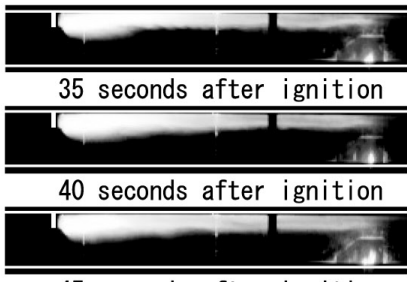

45 seconds after ignition

$\Delta \mathrm{Tc}=40(\mathrm{~K})$ Fire source position $\mathrm{b})$, Fire source No. $1, \mathrm{H}^{\prime}=150 \mathrm{~mm}, \mathrm{~W}^{\prime}=750 \mathrm{~mm}$

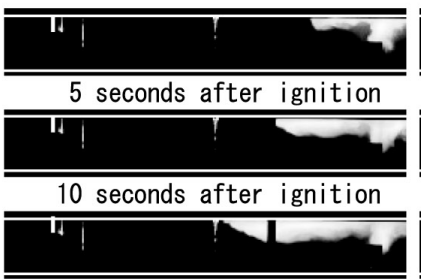

15 seconds after ignition

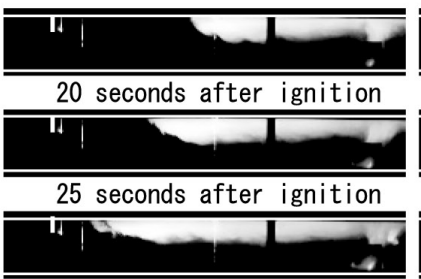

30 seconds after ignition

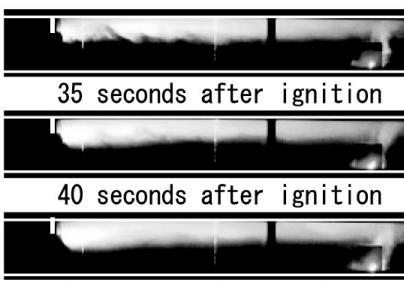

45 seconds after ignition $\Delta \mathrm{Tc}=60(\mathrm{~K})$ Fire source position b), Fire source No. 1, $H^{\prime}=150 \mathrm{~mm}, \mathrm{~W}^{\prime}=750 \mathrm{~mm}$

Figure 23 Effect of air current in the model on smoke interruption (visualized images)

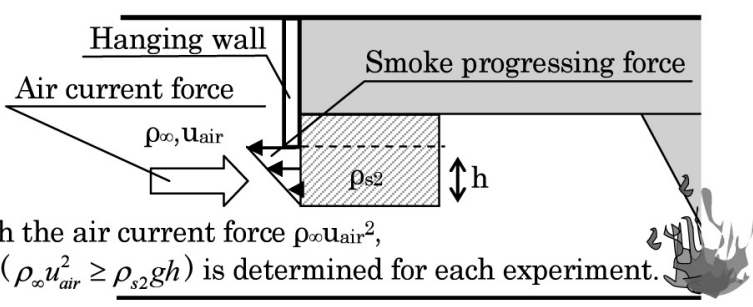

Figure 24 Concept of smoke interruption between the staircase and the fire room 
Experiments to confirm the smoke inflow into a staircase were conducted with $H^{\prime}, W^{\prime}$, and $\Delta T_{c}$ as parameters. To derive the boundary of smoke interruption success and failure, however, it is necessary to investigate the air current velocity under the hanging wall before smoke flows into a chimney under each experimental condition.

In the present study, using the relationship between the amount of ventilation per unit time calculated by Equation $27 V_{\text {cal }}$ and the amount of ventilation per unit time obtained by the pre-ignition ventilation amount experiment $V_{\text {exp. }}$ (Table 5, Figure 25), the calculated amount of ventilation was corrected (value obtained by Equation $27 \times 0.5$ ) to determine the air current velocity under the hanging wall under design conditions different than those given in Table 5.

$$
V_{\text {calculation }}=a A \sqrt{\frac{2 \Delta P_{c}}{\rho_{\infty}}}
$$

where $a=0.7(-)$ is the coefficient of flow rate, $a A\left(\mathrm{~m}^{2}\right)$ is the effective opening area when air supply opening, the opening under the hanging wall, and the chimney are connected in series, $\Delta P_{c}(\mathrm{~Pa})$ is the pressure difference due to the density difference between outside and inside air of the chimney (calculated from measurements with thermocouples in the chimney).

Table 5 Experimental conditions and results of the pre-ignition ventilation amount experiments

\begin{tabular}{|c|c|c|c|c|}
\hline $\begin{array}{l}\Delta \mathrm{Tc}_{\mathrm{c}} \\
(\mathrm{K})\end{array}$ & $\begin{array}{c}\mathrm{H}^{\prime} \\
(\mathrm{mm})\end{array}$ & $\begin{array}{c}W^{\prime} \\
(\mathrm{mm})\end{array}$ & $\begin{array}{c}\Delta \mathrm{P}_{\mathrm{o}} \\
\left(\mathrm{N} / \mathrm{m}^{2}\right)\end{array}$ & $\begin{array}{c}\text { Vexperiment } \\
\left(\mathrm{m}^{3} / \mathrm{s}\right)\end{array}$ \\
\hline \multirow{5}{*}{20} & 0 & 750 & 0.116 & 0.016 \\
\hline & \multirow{4}{*}{150} & 750 & 0.126 & 0.013 \\
\hline & & 600 & 0.102 & 0.018 \\
\hline & & 450 & 0.109 & 0.011 \\
\hline & & 300 & 0.114 & 0.009 \\
\hline \multirow{5}{*}{40} & 0 & 750 & 0.217 & 0.028 \\
\hline & \multirow{4}{*}{150} & 750 & 0.222 & 0.021 \\
\hline & & 600 & 0.201 & 0.022 \\
\hline & & 450 & 0.201 & 0.020 \\
\hline & & 300 & 0.226 & 0.012 \\
\hline \multirow{5}{*}{60} & 0 & 750 & 0.348 & 0.035 \\
\hline & \multirow{4}{*}{150} & 750 & 0.335 & 0.034 \\
\hline & & 600 & 0.316 & 0.032 \\
\hline & & 450 & 0.313 & 0.025 \\
\hline & & 300 & 0.347 & 0.017 \\
\hline
\end{tabular}

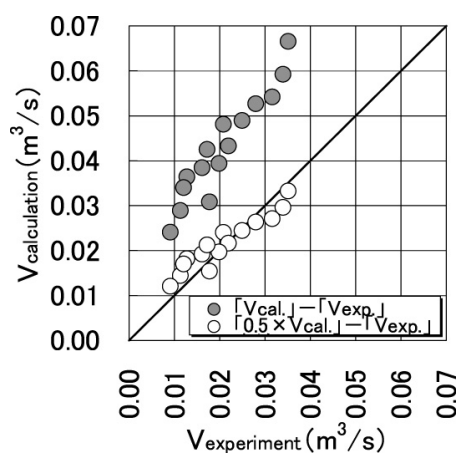

Figure25 Amount of ventilation per unit time 
Smoke interruption between the staircase and the fire room under the conditions of fire source No. $1\left(D_{f}=100 \mathrm{~mm}, Q=1.68 \mathrm{~kW}\right)$ was discussed in the following.

Figure 26 shows the experimental results and the boundaries of smoke interruption success and failure derived from the smoke behavior model for fire source positions a), b), and c). From Figure 26, we see that it becomes difficult to interrupt the smoke progressing at the hanging wall in the order of the fire source positions a), b), and c), because, if the fire source is close to a chimney, the smoke from the fire flows into the chimney before reaching the hanging wall, and the air current in the model grows.

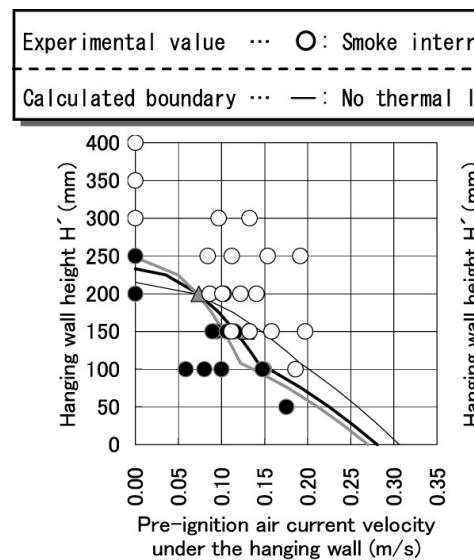

(a) Fire source position-a)

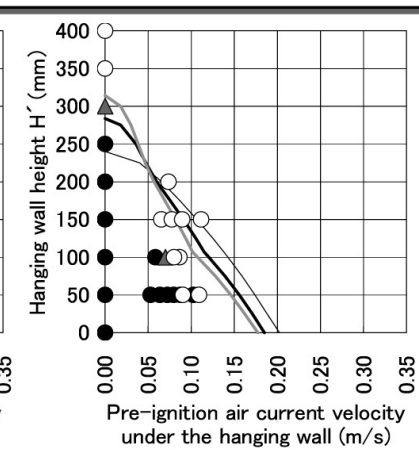

(b) Fire source position-b)

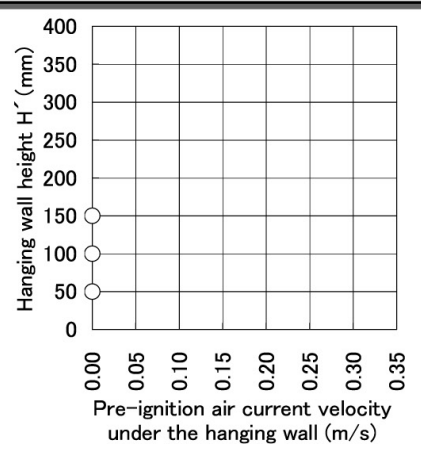

(c) Fire source position-c)
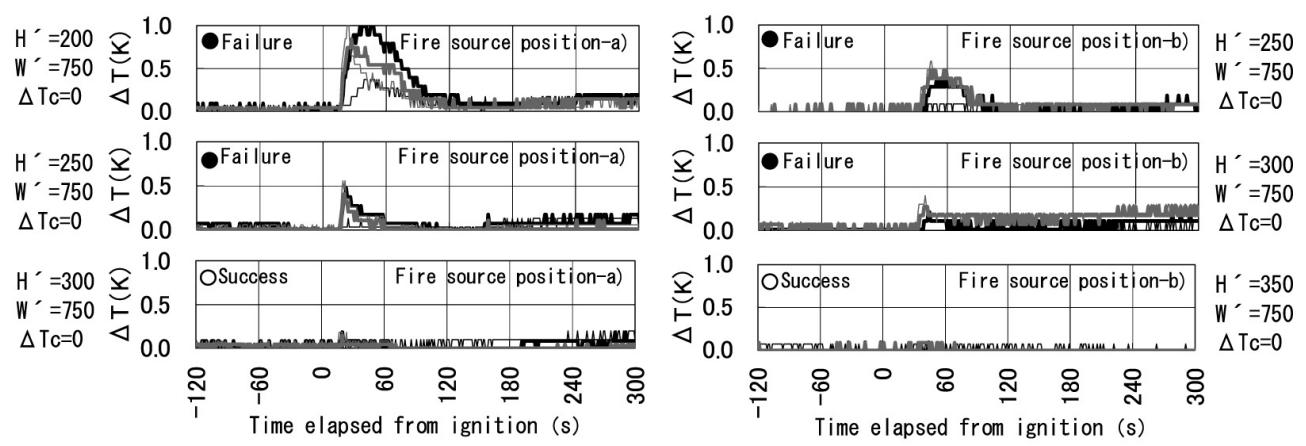

(d) Temperature rise at thermocouples in the staircase

Figure 26 Boundary of smoke interruption success and failure for various fire source positions

Under the conditions of fire source position a), the calculated boundaries match the experimental results well when the heat transfer between the lower part of the smoke layer and the air layer is considered.

Under the conditions of fire source position b) and the existence of air current velocity before ignition, the calculated air current velocity for smoke interruption is larger than the experimental result, probably because the smoke tip reached a chimney before the hanging wall, and a large air current may have been generated (this influence is not considered in the calculation). The calculated boundaries show different tendencies 
before and after for the hanging wall height of $115 \mathrm{~mm}$, because of the temperature difference between the upper and lower parts of the smoke layer.

Since a smoke layer is handled as a lump in the smoke propagation model, the temperature of smoke layer when the smoke tip reaches the hanging wall is estimated to be higher than the actual temperature around the hanging wall. Therefore, the prediction accuracy of the smoke behavior model proposed in the present study tends to become lower as the distance between the hanging wall and the fire source becomes longer. However, in an actual station building, the distance between the hanging wall and the fire source is not so long.

\section{CONCLUSION}

In Sections 1 to 3, the present study proposed a passive safety system that can realize both energy conservation in daily use and evacuation safety in the case of a fire for an underground station building. To evaluate this system, we conducted the $1 / 20$ scale model experiments based on the scaling laws and discussed the influence of parameter changes on the smoke behavior during a fire in a station building. Consequently, the following data was obtained. In the following, the heat release rate of the fire source is 3 MW on the actual scale.

- It was confirmed that the chimney size greatly affected the air current behavior in a station building in the case of a fire. In Model pattern I, the chimney of $425 \times 425 \mathrm{~mm}^{2}$ (equal to the air supply opening area) and $500 \mathrm{~mm}$ in height was found to have the greatest air supply and exhaust efficiency among the six types of chimneys prepared. If the air supply opening area, position, and quantity are changed, however, the optimum chimney size may also change. Therefore, actual design requires careful investigation.

- By changing the hanging wall height and the aisle width under the hanging wall in phases within a practical range in the experiments, we found the design conditions in which the smoke inflow into a staircase can be prevented in the case of a fire and the system can be operated effectively.

- By comparing the experimental results of Model pattern I and those of Model patterns II through IV, which support two evacuation routes to investigate the basic smoke behavior, we verified that more than one staircase would be disadvantageous for smoke interruption between the staircase and the fire room. For this system to function in the case of a fire, it is important to prevent smoke from entering a staircase before reaching a chimney after the occurrence of a fire and to clarify the conditions of smoke interruption.

In Sections 4 to 6, we fabricated a prediction model of the smoke propagation behavior in the early phase of a fire and of the smoke behavior after the smoke tip reaches the hanging wall in the horizontal long space, and compared the prediction results with the model experiment results for discussion. Consequently, the following data was obtained: 
- The prediction results by the two smoke behavior models proposed in the present study matched the experimental results well.

However, further discussion of proportional constants $C_{1}$ and $C_{2}$ in the equations, the temperature rise of the wall and ceiling surfaces contacted by the smoke layer, and the heat exchange between the lower part of the smoke layer and the air layer is necessary.

- Based on the assumption that the balance of the smoke progression force and the air current force determines the smoke inflow into a staircase, the boundary of smoke interruption success and failure between the staircase and the fire room was predicted.

As a result, the calculated boundary of smoke interruption matched the experimental results well.

\section{NOTE}

1) During winter, the air current in the direction of "outside air $\rightarrow$ staircase $\rightarrow$ concourse and platform $\rightarrow$ solar chimney $\rightarrow$ outside air" is formed because " $T_{\text {(chimney) }}$ $>T_{\text {(outside air)" }}$ and " $T_{\text {(outside air) }}<T_{\text {(station building) }}$ ", although no dry mist is sprayed above staircases ( $T$ : temperature). On rainy days or during an intermediate season, $T_{\text {(chimney), }}$, $T_{\text {(station building) }}$, and $T_{\text {(outside air) }}$ might be the same, and no natural convection occurs. This system controls air current by fine pressure difference balance between the inside and the outside of the underground station building. Even during the summer or the winter when the air current can be formed comparatively easily, air current required for smoke interruption may not be generated if the influence of pressure fluctuation between inside and outside of a station building becomes relatively large under certain meteorological conditions. Therefore, certain measures are required, including installing a gas lamp or similar auxiliary facilities inside a solar chimney for assistance if the solar chimney and dry mist sprayer cannot provide sufficient air current in the station building.

\section{SYMBOLS}

$\overline{\mathrm{u}}_{\mathrm{s} 1} \quad$ Average moving velocity of the tip of the upper part of the smoke layer $(\mathrm{m} / \mathrm{s})$

$\overline{\mathrm{u}}_{\mathrm{s} 2} \quad$ Average moving velocity of the tip of the lower part of the smoke layer $(\mathrm{m} / \mathrm{s})$

$\mathrm{u}_{\text {air }} \quad$ Air current velocity under the hanging wall $(\mathrm{m} / \mathrm{s})$

$\Delta \rho_{1} \quad$ Density difference between the upper part of the smoke layer and the ambient air $\left(\mathrm{kg} / \mathrm{m}^{3}\right)$

$\Delta \rho_{2} \quad$ Density difference between the lower part of the smoke layer and the ambient air $\left(\mathrm{kg} / \mathrm{m}^{3}\right)$

$\rho_{0} \quad$ Plume density at the point of inflow into the smoke layer $\left(\mathrm{kg} / \mathrm{m}^{3}\right)$

$\rho_{\mathrm{s} 1} \quad$ Density of the upper part of the smoke layer $\left(\mathrm{kg} / \mathrm{m}^{3}\right)$ 
$\rho_{\mathrm{s} 2} \quad$ Density of the lower part of the smoke layer $\left(\mathrm{kg} / \mathrm{m}^{3}\right)$

$\rho_{\infty} \quad$ Ambient air density $\left(\mathrm{kg} / \mathrm{m}^{3}\right)$

$\mathrm{T}_{0} \quad$ Plume temperature at the point of inflow into the smoke layer (K)

$\Delta T_{0} \quad$ Temperature rise on the central axis of the fire source (K)

$\Delta T_{\mathrm{c}} \quad$ Set temperature rise of the planar electric heaters (Temperature rise from the laboratory temperature) (K)

$\mathrm{w}_{0} \quad$ Axial flow velocity on the central axis of the file source $(\mathrm{m} / \mathrm{s})$

w Flow velocity toward the central axis of the file source $(\mathrm{m} / \mathrm{s})$

$\mathrm{T}_{\mathrm{s} 1} \quad$ Temperature of the upper part of the smoke layer $(\mathrm{K})$

$\mathrm{T}_{\mathrm{s} 2} \quad$ Temperature of the lower part of the smoke layer (K)

$\mathrm{T}_{\mathrm{w}} \quad$ Temperature of the wall or ceiling surface contacting the smoke layer (K)

$\mathrm{T}_{\infty} \quad$ Ambient air temperature (K)

$Q \quad$ Heat release rate of the fire source $(\mathrm{kW})$

$Q_{z^{\prime}}{ }^{*} \quad$ Non-dimensional heat release rate

$Q_{0} \quad$ Volumetric inflow per unit time from the plume into the smoke layer $\left(\mathrm{m}^{3} / \mathrm{s}\right)$

$Q_{s 1} \quad$ Volumetric flow rate per unit time at smoke tip $\left(\mathrm{m}^{3} / \mathrm{s}\right)$

$\mathrm{h}_{\mathrm{s} 1} \quad$ Thickness of the upper part of the smoke layer $(\mathrm{m})$

$\mathrm{h}_{\mathrm{s} 2} \quad$ Thickness of the lower part of the smoke layer $(\mathrm{m})$

$\mathrm{H}_{\mathrm{s}} \quad$ Thickness of the smoke layer $\left(=\mathrm{h}_{\mathrm{s} 1}+\mathrm{h}_{\mathrm{s} 2}(\mathrm{~m})\right)$

$\mathrm{X}_{1} \quad$ Horizontal distance from the central axis of the fire source to the tip of the upper part of the smoke layer $(\mathrm{m})$

$\mathrm{X}_{2} \quad$ Horizontal distance from the hanging wall to the tip of the lower part of the smoke layer $(\mathrm{m})$

g Gravitational acceleration $\left(\mathrm{m} / \mathrm{s}^{2}\right)$

$\mathrm{V}_{\mathrm{s} 1} \quad$ Volume of the upper part of the smoke layer $\left(\mathrm{m}^{3}\right)$

$\mathrm{V}_{\mathrm{s} 2} \quad$ Volume of the lower part of the smoke layer $\left(\mathrm{m}^{3}\right)$

$\mathrm{A}_{\mathrm{s} 1} \quad$ Area of contact between the upper part of the smoke layer and the surrounding wall $\left(\mathrm{m}^{2}\right)$

$\mathrm{A}_{\mathrm{s} 2} \quad$ Area of contact between the lower part of the smoke layer and the surrounding wall $\left(\mathrm{m}^{2}\right)$

$\mathrm{A}_{\mathrm{s} 3} \quad$ Area of contact between the lower part of the smoke layer and the air layer $\left(\mathrm{m}^{2}\right)$

$\mathrm{A}_{\mathrm{f}} \quad$ Area of the fire source $\left(\mathrm{m}^{2}\right)$

$H^{\prime} \quad$ Hanging wall height $(\mathrm{mm})$

$W^{\prime} \quad$ Aisle width under the hanging wall $(\mathrm{mm})$

$\mathrm{D}_{\mathrm{f}} \quad$ Diameter of the fire source $(\mathrm{mm})$

a Total thermal conductivity by convection and radiation in ordinary environmental engineering $\left(=0.023\left(\mathrm{~kW} / \mathrm{m}^{2} / \mathrm{K}\right)\right)$

$\mathrm{C}_{\mathrm{p}} \quad$ Constant-pressure specific heat $(=1(\mathrm{~kJ} / \mathrm{kg} / \mathrm{K}))$

$\mathrm{b}_{\mathrm{p}} \quad$ Plume width $(\mathrm{m})$

$\mathrm{r} \quad$ Horizontal distance from the central axis of the fire source $(\mathrm{m})$

$\mathrm{z}_{0} \quad$ Virtual-point heat source height $(\mathrm{m})$

$\mathrm{B}_{\mathrm{S}} \quad$ Flow width $(\mathrm{m})$ 


\section{APPENDIX}

- Influence of model materials not conforming to the scaling laws

For an underground station building of actual size with bare concrete ceilings, walls, and floors, a 1/20 scale model should be made of cedar (water content: $0 \%$ ) according to the scaling laws in Equation 5. If the model is made of acryl, the thermal characteristic $\lambda \rho c$ calculated by Equation 5 is $31.30\left(\mathrm{~kW}^{2} \cdot \mathrm{s} / \mathrm{m}^{4} \mathrm{~K}^{2}\right)$ on the actual scale. This corresponds approximately to that of carbon brick (Table 6).

Table 6 Thermophysical properties of materials ${ }^{67)}$

\begin{tabular}{l|c|c|c|c}
\hline \multicolumn{1}{c|}{ Material } & $\rho\left(\mathrm{kg} / \mathrm{m}^{3}\right)$ & $c(\mathrm{~kJ} / \mathrm{kg} \cdot \mathrm{K})$ & $\lambda(\mathrm{kW} / \mathrm{m} \cdot \mathrm{K})$ & $\lambda \rho c\left(\mathrm{~kW} \cdot \mathrm{s} / \mathrm{m}^{4} \mathrm{~K}^{2}\right)$ \\
\hline Ordinary concrete & 2200 & 0.88 & $1.5 \times 10^{-3}$ & 2.92 \\
\hline Cedar(water content $0 \%)$ & 300 & 1.30 & $6.9 \times 10^{-5}$ & $2.69 \times 10^{-2}$ \\
\hline Acryl & 1190 & 1.40 & $2.1 \times 10^{-4}$ & $3.50 \times 10^{-1}$ \\
\hline Plaster board & 863 & 1.13 & $1.6 \times 10^{-4}$ & $1.56 \times 10^{-1}$ \\
\hline Carbon brick & 1580 & 1.40 & $1.7 \times 10^{-2}$ & 37.60 \\
\hline
\end{tabular}

Based on the above, if a model made of the materials described in Section 2.1 is used for the experiments, the smoke layer temperature at a certain point in the model will be slightly lower than for a model made of cedar (water content: 0\%). This section specifically discusses temperature differences due to the materials of model.

For calculation, Fire Dynamics Simulator Version 4.06 (hereinafter, FDS) of the National Institute of Standards and Technology (NIST) was used. The discretization method is a finite volume method. The second-order accurate predictor-correlator method was adopted for the temporal discretization scheme and the second-order accurate central difference was adopted for the spatial differential scheme. For the advective term, the first-order accurate upwind-biased difference was applied to the corrective terms at the phase of prediction and the first-order accurate downwind-biased difference at the phase of correction. To reproduce a turbulent flow, LES was used for calculation (for the SGS model, the standard Smagorinsky model was used $\left(C_{s}=0.2\right)$ ). For the combustion model, the Mixture Fraction Combustion Model was used. In calculation, the influence of heat radiation between walls was also considered. The calculation area was created by linking the two rectangular parallelepiped domains of $8,750 \mathrm{~L} \times 850 \mathrm{~W} \times 700 \mathrm{H}$ $\mathrm{mm}^{3}$ and $1,350 \mathrm{~L} \times 850 \mathrm{~W} \times 1,300 \mathrm{H} \mathrm{mm}^{3}$. The compartment for which the dimensions are the same as those of the experimental model (Model pattern I) used in Sections 2 and 3 is located in this area. Figure 27 shows an outline of the calculation area. 


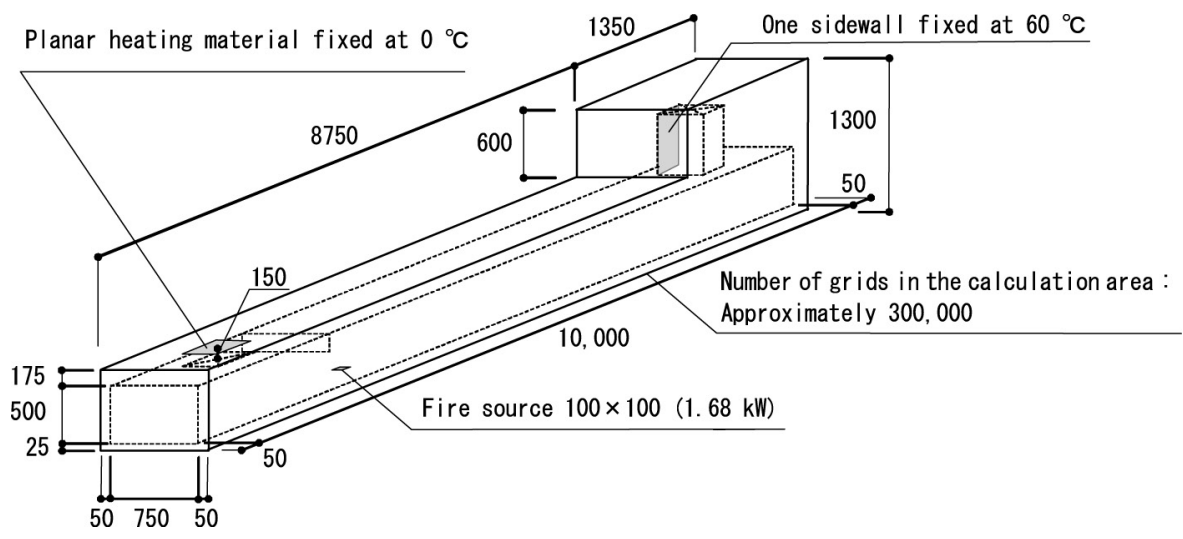

Figure 27 Outline of the calculation area (Unit: $\mathrm{mm}$ )

As the boundary conditions, the air temperature and wall surface temperature in the calculation area at the start of calculation were set equal to the laboratory temperature during the experiment, and the same wall materials and fire source as those for the experiment were used. To reproduce the chiller and planar electric heater, a planar heat source of the same size as the air supply opening $\left(600 \times 300 \mathrm{~mm}^{2}\right)$ fixed at $0^{\circ} \mathrm{C}$ was installed $150 \mathrm{~mm}$ above the air supply opening, and one of the side walls of the chimney at the same position as the model was fixed at $60^{\circ} \mathrm{C}$.

Heat release rate of $1.68 \mathrm{~kW}$ was given to the fire source of $100 \times 100 \mathrm{~mm}^{2} 300$ seconds after the start of calculation, and the calculation was completed in 1,800 seconds. In this section, each calculation was performed only by changing the model materials under the experimental condition No. 1 in Table 2.

Figure 28 shows the vertical distributions of average temperature rise at position-B and D shown in Figure 34 to 5 minutes and 29 to 30 minutes after ignition. The vertical distribution of temperature rise at position-B (hanging wall position) shows a maximum difference of approximately $4 \mathrm{~K}$ inside the smoke layer 4 to 5 minutes after ignition and of approximately $7 \mathrm{~K} 29$ to 30 minutes after ignition. Despite these differences, however, their smoke layer heights matched. At position-D, which is three meters away from the fire source toward the chimney in the $1 / 20$ scale model, the temperature difference of the smoke layer by model materials is very small.

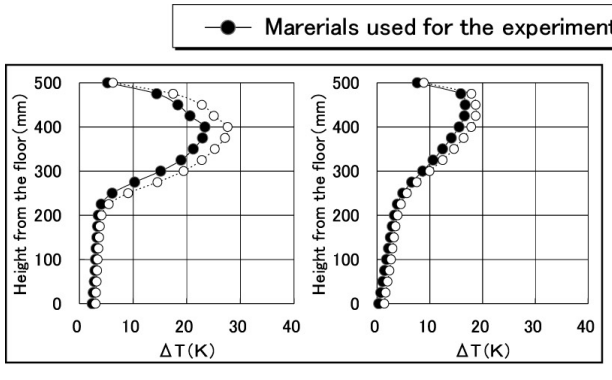

Position-B

Position-D

(a) Average 4 to 5 minutes after ignition

.. Cedar ( water content $0 \%$ )

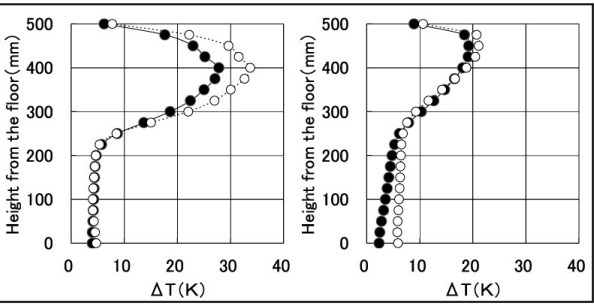

Position-B

Position-D

(b) Average 29 to 30 minutes after ignition

Figure 28 Vertical distributions of temperature rise in the model by model materials (FDS) 


\section{REFERENCES}

1. S.W.Cho and K.Kimura, Study on the performance prediction of solar chimney in natural ventilation system for a school building, Journal of Environmental Engineering No.537, Architectural Institute of Japan, pp.37-42, 2000 (in Japanese)

2. M.Tsujimoto, M.Okumiya and M.Harada, Dry water mist spray system to control urban heat island problem -Its concept and elementary assessment -, Journal of the meeting for reading research papers No.4, Chubu Branch of The Society of Heating, Air-Conditioning and Sanitary Engineers of Japan, pp.63-64, 2003 (in Japanese)

3. M.Tsujimoto and S.Uehara, A scaling law of smoke movement in atrium, 11th UJNR on Fire Research and Safety, pp.181-187, 1989

4. T.Tokunaga et al., Understanding of the smoke movement in a station building during a fire by the model experiments - Basic study on passive smoke control system in an underground station using the daily natural ventilation -, Journal of Environmental Engineering No.616, Architectural Institute of Japan, pp.9-16, 2007 (in Japanese)

5. T.Matsushita and T.Wakamatsu, Mathematical model and experiments of spread of smoke front in a corridor -Horizontal spread of smoke front Part 1-, Journal of Structural and Construction Engineering No.468, Architectural Institute of Japan, pp.193-198, 1995 (in Japanese)

6. T.Tanaka, An introduction to fire safety engineering of architecture, The Building Center of Japan, 1993 (in Japanese)

7. The Japan Society of Mechanical Engineers, Heat transfer engineering data, pp.320-322, 1986 (in Japanese) 